\title{
Electrical conductivity and induced polarization investigations at Krafla volcano, Iceland
}

\author{
A. Revil ${ }^{\text {a,* }}$, Y. Qi $^{\text {a }}$, A. Ghorbani ${ }^{\text {b }}$, A. Soueid Ahmed ${ }^{\text {a }}$, T. Ricci ${ }^{\text {c }}$, P. Labazuy ${ }^{\mathrm{d}}$ \\ a Université Grenoble Alpes, Université Savoie Mont Blanc, CNRS, IRD, IFSTTAR, ISTerre, 38000 Grenoble, France \\ b Department of Mining and Metallurgical Engineering, Yazd University, Yazd, Iran \\ ' Istituto Nazionale di Geofisica e Vulcanologia, Rome, Italy \\ d Université Clermont Auvergne, CNRS, IRD, OPGC, Laboratoire Magmas et Volcans, F-63000 Clermont-Ferrand, France
}

\section{A R T I C L E I N F O}

\section{Article history:}

Received 21 August 2018

Received in revised form 9 November 2018

Accepted 10 November 2018

Available online 13 November 2018

\begin{abstract}
A B S T R A C T
Electrical conductivity and polarization properties of 6 samples from Krafla volcano (Iceland) were measured in the frequency range $1 \mathrm{mHz}-45 \mathrm{kHz}$ and compared to the data obtained on various basaltic rock samples from Hawaii. The results indicate that for altered samples, the surface conductivity, normalized chargeability, and quadrature conductivity of the core samples scales linearly with the cation exchange capacity, taken as a proxy of the alteration facies. The surface conductivity of fresh samples is also controlled by the cation exchange capacity but their normalized chargeability is influenced by the presence of magnetite, especially for unaltered samples. The temperature dependence of quadrature conductivity and normalized chargeability can be modeled with an $\mathrm{Ar}$ rhenius equation with an activation energy of $16-19 \mathrm{~kJ} \mathrm{~mol}^{-1}$. The experimental results agree with a model in which the polarization of the metallic and non-metallic grains are both considered in a unified framework. These results are used to interpret two 3D induced polarization surveys performed in the South and East parts of Krafla volcano using two $1.3 \mathrm{~km}$-long cables with 32 electrodes each. The electrical conductivity is in the range 0.3 (clay cap) to $5 \times 10^{-5} \mathrm{~S} \mathrm{~m}^{-1}$ (unaltered rock) while the normalized chargeability is typically comprised between $10^{-2}$ (clay cap) and $10^{-5} \mathrm{~S} \mathrm{~m}^{-1}$ (unaltered rock). Induced polarization is used to image porosity and the cation exchange capacity. A long $5.6 \mathrm{~km}$ electrical conductivity profile was also performed connecting the two 3D sites and crossing a rhyolitic obsidian ridge called Hrafntinnuhryggur. Hrafntinnuhryggur is characterized by very low conductivity values on the order of $10^{-4} \mathrm{~S} \mathrm{~m}^{-1}$. The long conductivity profile shows the position of the inner and outer caldera rims and the feeder dike of Hrafntinnuhryggur. A self-potential survey performed along this long profile shows no shallow active geothermal features in this area, as expected from the low permeability of the clay cap.
\end{abstract}

(C) 2018 Published by Elsevier B.V.

\section{Introduction}

Galvanometric geoelectrical methods provide very useful information to image the inner structure of volcanoes including alteration, clay caps, and their hydrothermal plumbing system. For instance, the self-potential method can be used to track the pattern of ground water flow in the field (Birch, 1993, 1998; Perrier et al., 1998) and the presence of ores (Corwin, 1989; Bigalke and Grabner, 1997). Electrical conductivity/resistivity tomography has shown to be a very useful method to image geothermal systems to a depth of few kilometers and, in some instance, alteration, magmatic brines, and magmatic chambers (Reid et al., 2001; Bernard et al., 2007; Finizola et al., 2010;

\footnotetext{
* Corresponding author.

E-mail addresses: andre.revil@univ-smb.fr (A. Revil), uzhengqi@gmail.com (Y. Qi), ah.ghorbani@yahoo.fr (A. Ghorbani), abdellahi.soueid-ahmed@univ-smb.fr (A. Soueid Ahmed), tullio.ricci@ingv.it (T. Ricci), P.Labazuy@opgc.fr (P. Labazuy).
}

Revil et al., 2010; Barde-Cabusson et al., 2013). Another geoelectrical method, induced polarization, has the potential to complement electrical conductivity tomography to image more specifically the alteration of volcanoes but its response is also influenced by the presence of semiconductors such as pyrite and magnetite (e.g., Wong, 1979; Revil et al., 2015a, 2015b). Induced polarization has a long history in geophysics (Schlumberger, 1920; Shuey and Johnson, 1973; Olhoeft, 1985) and has been barely used in this type of environments. Works in this direction are recent and mostly focused on the development of the background theory and laboratory investigations (Revil et al., 2017a; Ghorbani et al., 2018). Field studies are still missing to date.

The main goal of the present study is to test the ability of the induced polarization method to be sensitive to alteration and to determine parameters of high interest in geothermal systems. It combines field and experimental works. Electrical conductivity alone cannot be considered as directly sensitive to alteration and rocks belonging to different facies can have the same electrical conductivity. Indeed, electrical conductivity 
depends on two main contributions: a bulk conductivity controlled by the conductivity of the brine in the interconnected pore space and a so-called surface conductivity corresponding to the conduction in the electrical double layer coating the surface of the grains (e.g., Waxman and Smits, 1968; Revil et al., 1998). Only the second contribution is sensitive to the alteration of the volcanic rocks (e.g., Soueid Ahmed et al., 2018). At the opposite, parameters deduced from induced polarization (such as quadrature conductivity and normalized chargeability) can be directly used as proxies of the alteration facies of volcanic rocks (Revil et al., 2017a; Ghorbani et al., 2018). This is true at least as long as the fraction of pyrite and magnetite remains small (typically $<1 \%$, see discussions in Ghorbani et al., 2018).

In the present paper, we decided to go one step further by combining a petrophysical study using 6 samples from Krafla with a geophysical study including three dimensional DC (Direct Current) conductivity and chargeability tomography at 2 sites on Krafla volcano. In addition, we performed a $5.7 \mathrm{~km}$-long conductivity profile crossing the Obsidian Ridge (Hrafntinnuhryggur) and the inner caldera rim of the volcanic system.

Krafla is a very active volcanic system located on the Northern Volcanic Zone (NVZ) of Iceland. It is associated with the subaerial part of the divergent plate margins of Mid-Atlantic Ridge (e.g., Drouin et al., 2016). The structure of the NVZ is characterized by the presence of several volcanic systems. The NVZ is delimited by the offshore Tjórnes Fracture Zone to the North and by the Vatnajökull ice cap to the South. The basaltic fissure swarm crossing this volcano is $90 \mathrm{~km}$ long and 5-8 km wide (Sæmundsson, 1983; Hjartardóttir et al., 2012). This fissure swarm is the expression of rifting with repeated episodes of dike intrusions. Krafla, one of these volcanic systems, consists of a central volcano and an associated en echelon-arranged NNE-trending fissure swarm (Sæmundsson, 1974; Hjartardóttir et al., 2015). The outer caldera, bordered by rhyolitic domes (Drouin et al., 2016, 2017), measures about $7 \mathrm{~km} \mathrm{N-S}$ and 9 km E-W and was probably formed about 110,000 years ago during an interglacial period at the beginning of the first rhyolitic volcanism phase of Krafla volcano and then filled by repeated eruptions (Sigvaldason, 1983; Árnason et al., 2010). A younger inner caldera, formed sometime between 80,000 and 40,000 years ago, has also been observed (Árnason et al., 2010) but the position of the rims of this caldera is not always clearly visible. During the Holocene, Krafla volcanic system was characterized by two periods of extended eruptive activity. The current one began around 2600-2800 years ago (Sæmundsson, 1991). In the last 1100 years, two major volcano-tectonic rifting episodes were reported. The first one, Mývatn Fires, occurred during the period 1724-1729 (Thoroddsen, 1907-1915) while the second one, Krafla Fires, occurred during the period 1975-1984 (Einarsson, 1991; Buck et al., 2006). In the course of Krafla Fires, 21 rifting events and nine basaltic fissure eruptions took place as a result of dike intrusions while at least 10 intruded dikes did not reach the surface (Tryggvason, 1984; Bjornsson et al., 2006).

The shallow electrical conductivity structure of the Krafla geothermal area has been studied by both Schlumberger and dipole-dipole galvanometric soundings and profiling plus time-domain Electro-Magnetic (TDEM) soundings (Árnason and Karlsdóttir, 1996; Árnason and Magnússon, 2001). These surveys have provided some important information regarding the geothermal activity in the uppermost $1 \mathrm{~km}$ of this volcanic system. These studies were complemented by magnetotelluric (MT) investigations to study the deeper parts $(>1 \mathrm{~km})$ of the geothermal system of Krafla (Árnason et al., 2010). Experimental works using volcanic rocks from Iceland have also pointed out the role of surface conductivity (Flóvenz et al., 2005; Kristinsdóttir et al., 2010) as an important contribution to the overall conductivity of the volcanic rocks. This is especially true because of alteration and the low mineralization of the ground waters in this volcano.

In the present survey, we investigated only a small portion of Krafla volcano in order to test the methodology we developed in our previous papers (Revil et al., 2017a; Ghorbani et al., 2018). Our goal is to use these new data to reply to the following questions: (1) What is the effect of magnetite on the induced polarization response of volcanic rocks at
Krafla? (2) Is surface conductivity really the dominant conduction process at Krafla? (3) Can quadrature conductivity and normalized chargeability be reliable indicators of the alteration facies? (4) What is the electrical conductivity of the obsidian ridge and can we see the feeder dike responsible for its genesis? (5) What is the conductivity and induced polarization properties of the clay cap? (6) And finally, can we observe the caldera boundaries at Krafla with electrical conductivity tomography?

\section{Background theory}

\subsection{Petrophysics}

Electrical conductivity describes the ability of a rock to conduct an electrical current, i.e., a flow/flux of electrical charges. Chargeability describes the ability of a porous rock to store reversibly electrical charge during the passage of a (primary) electrical current. In this paper, we are interested in the interpretation of time-domain induced polarization (TDIP) data such as sketched in Fig. 1. TDIP measurements are preferred over frequency-domain induced polarization because of their easiness to be carried out in the field with most resistivity meters. In TDIP, a primary current is injected in the ground over a period $T$ using two current electrodes A and B. Once this current is shut down, the secondary voltage is recorded between two potential electrodes $\mathrm{M}$ and $\mathrm{N}$. The existence of a secondary voltage implies that the subsurface of the volcanic edifice has stored reversibly electrical charges (for instance ionic charges around the non-metallic grains and p-holes and electrons, the two charge carriers, inside semi-conductors such as pyrite and magnetite, see Figs. 2 and 3). Another way to see such low-frequency $(<1 \mathrm{kHz})$ polarization is to say that the electrical conductivity is dispersive, i.e., frequency dependent (Seigel, 1959). Frequency-domain induced polarization (FDIP) measurements are usually done in the laboratory to characterize the complex conductivity of porous rocks. Under certain conditions (especially that TDIP been carried out at various periods in the injected current), TDIP and FDIP can bring the same type of information regarding the conduction and polarization properties of rocks (see discussion in Ghorbani et al., 2007).

The frequency dependence of the electrical conductivity can be built starting with its two end-members plus a distribution of relaxation times. In the following, the quantity $\sigma_{\infty}$ denotes the instantaneous (i.e., high-frequency) conductivity, i.e., the conductivity when all the charge carriers are mobile under the action of a primary electrical field (see Figs. 2 and 3). Indeed, it takes a certain amount of time for the material to polarize. The quantity $\sigma_{0}$ denotes the Direct Current (DC) conductivity of the material, i.e., the conductivity obtained when the material has been exposed to an external (applied) electrical field for a long time. This state is therefore reached when some of the charge carriers have attained a certain pseudo-equilibrium state under the action of the primary (external or applied) electrical field or primary electrical current. Therefore $\sigma_{0}$ corresponds to the low frequency limit of the electrical conductivity spectrum. Classical conductivity tomography provides a conductivity that is given at a frequency corresponding to the main frequency contained in the current waveform (for a box-current, it is determined from the period). As a first approximation, we can consider that this is close enough to the DC conductivity.

The chargeability $M$ (dimensionless) and the normalized chargeability $M_{n}\left(\mathrm{~S} \mathrm{~m}^{-1}\right)$ can be defined in terms of the characteristics of the conductivity dispersion curve (Seigel, 1959) as

$M=\frac{\sigma_{\infty}-\sigma_{0}}{\sigma_{\infty}}$,

$M_{n}=\sigma_{\infty}-\sigma_{0}$.

As a side note, it is unfortunate that the label "normalized chargeability" is not associated with Eq. (1), which would be more 
a. Time series in induced polarization

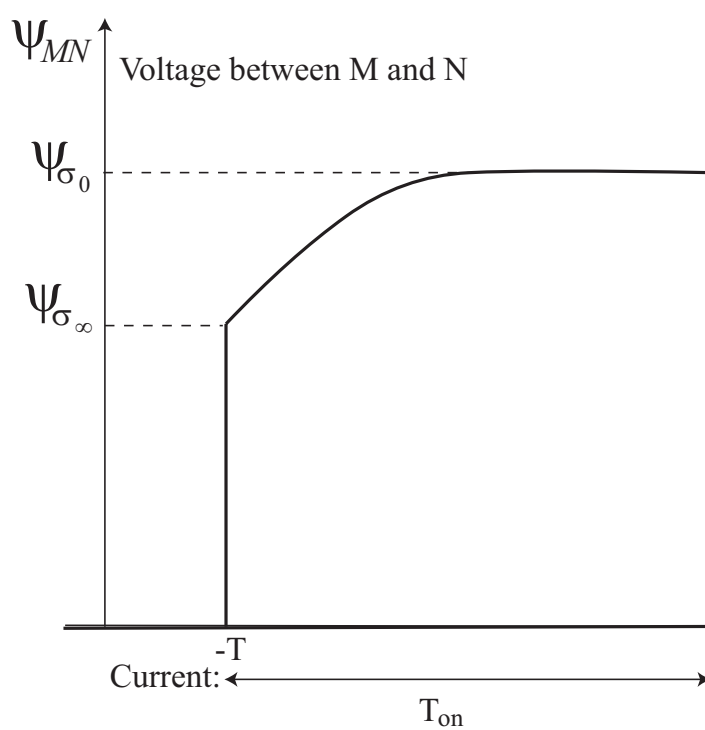

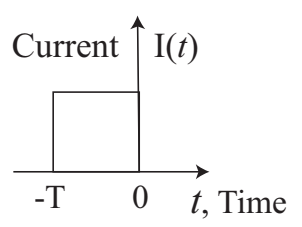

Secondary voltage decay

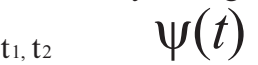

b. Spatial configuration

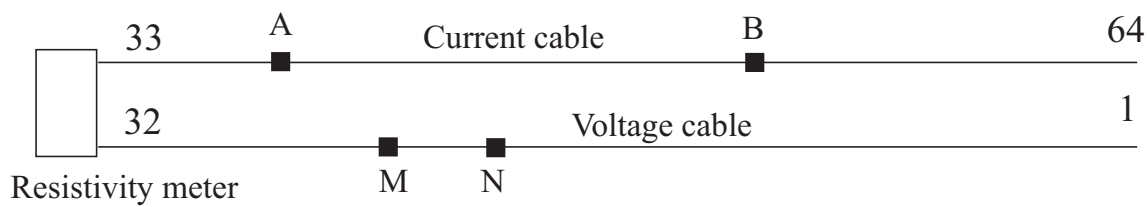

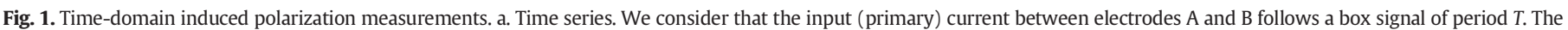

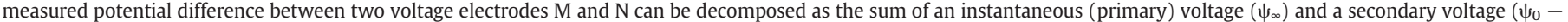

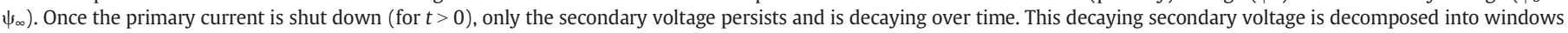

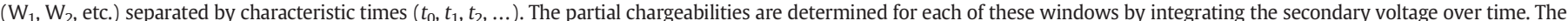

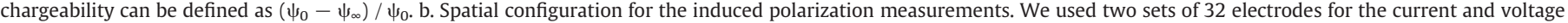
electrodes, which are located on two distinct set of cables (each $1240 \mathrm{~m}$-long).

intuitive. We only use here the names currently used in the literature and developed over time. There are also other ways to determine the chargeability based on the secondary voltage decay after the shut-down of the primary current (Fig. 1) or using the relationships that can be established (under additional assumptions) between the chargeability and the phase (e.g., Shuey and Johnson, 1973; Revil et al., 2017b).

In the present paper, we are interested in the dependence of the chargeability (and normalized chargeability) with alteration. The cation exchange capacity (CEC) describes the quantity (in equivalent electrical charge) of the active (exchangeable) sites on the surface of minerals per unit mass of minerals. Typically, the CEC is controlled by the presence of clays and zeolites, both produced during the alteration of volcanic rocks. This is because of the high specific surface area of these types of minerals. Therefore, the CEC can be used as a proxy of alteration (Revil et al., 2017a) or more precisely as a proxy of alteration facies including the smectite-rich clay cap (for smectite, the interlayer charge should be accounted for, see Leroy and Revil, 2009) and the higher temperature facies rich in chlorite. Chargeability is also dependent on the volume content of metallic particles $\varphi_{m}$ including pyrite and magnetite (Wong, 1979; Revil et al., 2015a, 2015b).

In order to go further, we consider the general case of an electrolytesaturated porous volcanic rock with insulating minerals plus pyrite and/ or magnetite. In such a case, both the non-metallic and the metallic grains polarize but the underlying polarization mechanisms are distinct as shown in Figs. 2 and 3. The chargeability $M$ of this mixture is directly related to the (dimensionless) volume content of metallic particles and to the background properties by (Revil et al., 2015a, 2015b),

$M \approx \frac{9}{2} \varphi_{m}+M_{b}$ where $M_{b}$ (dimensionless) denotes the chargeability of the background material (non-metallic grains saturated by the electrolyte) and $\varphi_{m}$ denotes the volume fraction of metallic particles (here pyrite and especially magnetite). The instantaneous and DC conductivities of the mixture (background plus metallic particles) are related to the instantaneous conductivity of the background alone $\left(\sigma_{b}^{\infty}\right)$ and to the DC conductivity of the background ( $\sigma_{b}^{0}$ ) according to (Revil et al., 2015a, 2015b),

$\sigma_{\infty} \approx \sigma_{b}^{\infty}\left(1+3 \varphi_{m}\right)$,
$\sigma_{0} \approx \sigma_{b}^{0}\left(1-\frac{3}{2} \varphi_{m}\right)$.

The chargeability of the background is defined as the ratio between the normalized chargeability of the background and the instantaneous conductivity of the background material,

$M_{b}=\frac{M_{n}^{b}}{\sigma_{\infty}^{b}}=\frac{\sigma_{\infty}^{b}-\sigma_{0}^{b}}{\sigma_{\infty}^{b}}$

In order to go further, we need a model for the polarization of the non-metallic grains shown in Fig. 2. More information regarding the polarization of the double layer can be found in Lyklema et al. (1983) and Leroy et al. (2017). According to the dynamic Stern layer model developed by Revil (2012, 2013a, 2013b), the normalized chargeability (entering Eq. (6)) and instantaneous conductivity of the background material entering Eq. (4) can be written as (Revil et al., 2017a),

$M_{n}^{b}=\theta^{m-1} \rho_{g} \lambda \mathrm{CEC}$, 
a. $t=0^{+}$
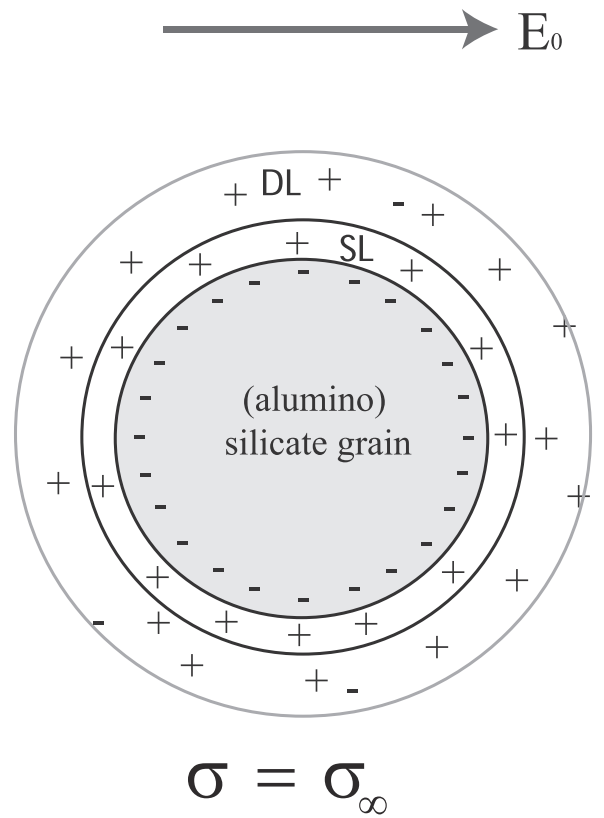

$\mathrm{E}_{0}$ b.

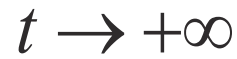

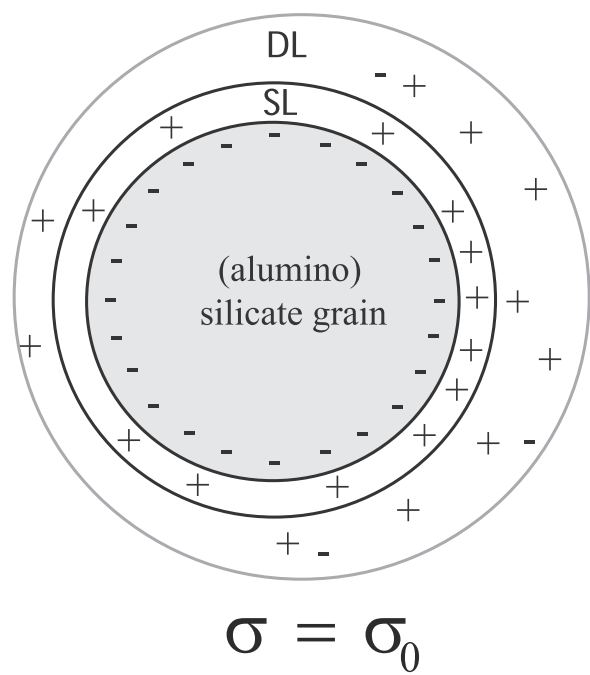

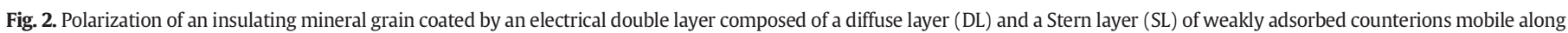

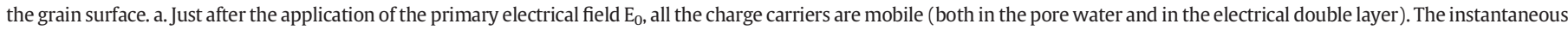

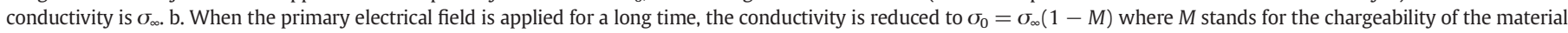

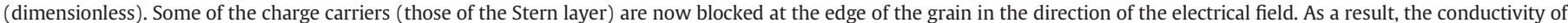

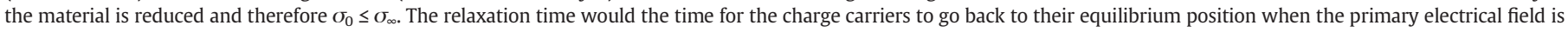
shut down. In a porous material, these grains are immersed in a polarizable background made by the other grains.

$\sigma_{\infty}^{b}=\theta^{m} \sigma_{w}+\theta^{m-1} \rho_{g} B C E C$,

where $\theta$ (dimensionless) denotes the water content (product of the porosity and the saturation of the pore water phase considered as the wetting fluid), $m$ (dimensionless) denotes the porosity (or cementation) exponent, $\sigma_{w}$ (in $\mathrm{S} \mathrm{m}^{-1}$ ) denotes the pore water conductivity, $\rho_{g}$ is the grain density (in $\mathrm{kg} \mathrm{m}^{-3}$ ), and CEC denotes the cation exchange capacity (in $\mathrm{C} \mathrm{kg}^{-1}$ ). The quantity $\theta$ denotes the volume of water over the volume of rock. For the basalts from Krafla, Flóvenz et al. (2005) obtained a grain density $\rho_{g}=2950 \mathrm{~kg} \mathrm{~m}^{-3}$. The CEC denotes the quantity
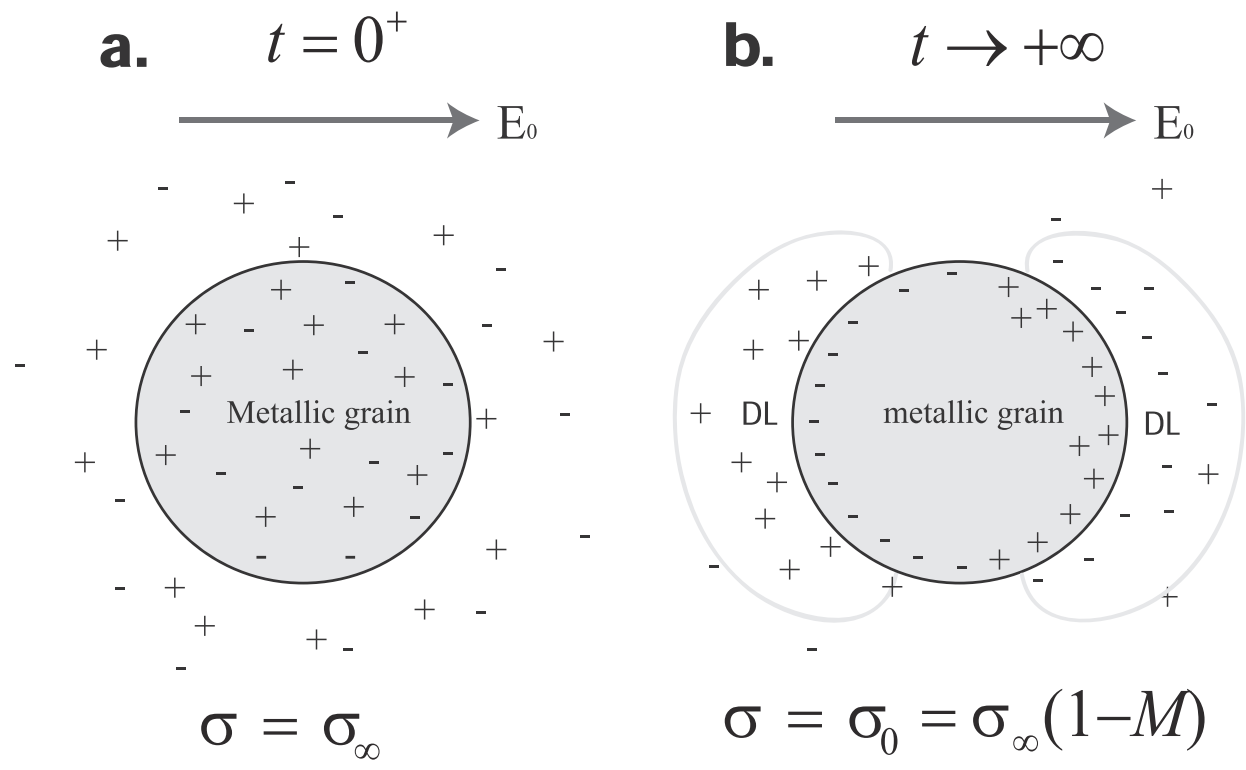

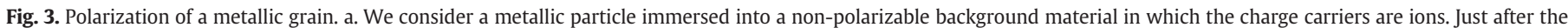

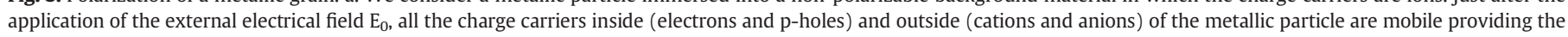

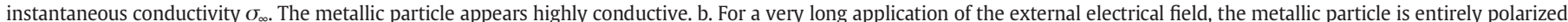

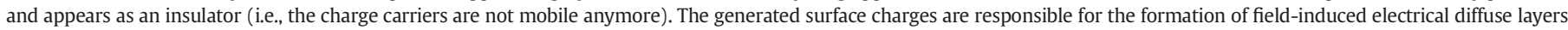

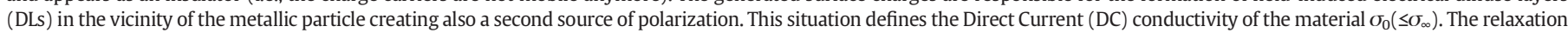
time would the characteristic time for the charge carriers to go back to their equilibrium position when the primary electrical field is shut down. 
of exchangeable cation on the surface of minerals. The last term of Eq. (8) corresponds to the so-called surface conductivity $\sigma_{S}=\theta^{m-1} \rho_{g} B$ CEC. In Eq. (8), $B\left(\right.$ in $\mathrm{m}^{2} \mathrm{~V}^{-1} \mathrm{~s}^{-1}$ ) denotes the apparent mobility of the counterions for surface conduction in Fig. 2 (Waxman and Smits, 1968) with $B\left(\mathrm{Na}^{+}, 25^{\circ} \mathrm{C}\right)=4.1 \times 10^{-9} \mathrm{~m}^{-2} \mathrm{~s}^{-1} \mathrm{~V}^{-1}$ (Revil et al., 2017a, 2017b and some discussion in Waxman and Smits, 1968). The quantity $\lambda$ (in $\mathrm{m}^{2} \mathrm{~V}^{-1} \mathrm{~s}^{-1}$ ) denotes the apparent mobility of the counterions for the polarization (Fig. 2) associated with the quadrature conductivity and $\lambda\left(\mathrm{Na}^{+}, 25^{\circ} \mathrm{C}\right)=3.46 \times 10^{-10} \mathrm{~m}^{-2} \mathrm{~s}^{-1} \mathrm{~V}^{-1}$ (Vinegar and Waxman, 1984). The temperature dependence of $B, \lambda$, and $\sigma_{w}$ can be modeled with an Arrhenius's law (see Appendix A for details).

In developing Eqs. (7) and (8), we have assumed that the porosity and saturation exponents ( $m$ and $n$, respectively) are equal (see Revil et al., 2017a, 2017b, 2018, for a more complete model). From Eqs. (6), (7), and (8), the DC conductivity of the background material entering Eq. (5) can be written as:

$\sigma_{0}^{b}=\theta^{m} \sigma_{w}+\theta^{m-1} \rho_{g}(B-\lambda)$ CEC.

We now introduce the key dimensionless number $\mathrm{R}$ given by $\mathrm{R}=\lambda$ / $B$. This dimensionless number is also defined to be the ratio between the normalized chargeability (Eq. (7)) and the surface conductivity (see the last term of Eq. (8)). For further details, the reader is directed to Revil (2013a, 2013b) and Weller et al. (2013). This dimensionless number is independent of saturation. It is also independent of temperature since the temperature dependence of $\lambda$ and $B$ is the same (Appendix A). Finally, an expression of the chargeability of the background material in Eq. (3) can be obtained using Eqs. (5) to (8)

$M_{b}=\frac{\rho_{g} \lambda \mathrm{CEC}}{\theta \sigma_{w}+\rho_{g} B C E C}$

At low salinities, when surface conductivity dominates the pore water conductivity ( $\mathrm{Du} \gg 1, \mathrm{Du}=\rho_{\mathrm{g}} B \mathrm{CEC} / \sigma_{w} \phi$ is called the dimensionless Dukhin number), we obtain the simplified result for the chargeability of the background,

$\lim _{\text {Du } \gg 1} M_{b}=\frac{\lambda}{B}=R$

This means that there is a universal value $R$ (independent of temperature and saturation) for the limit of the chargeability of the background material shown in Fig. 1 at low salinities. In absence of metallic particles, when the chargeability reaches this limit, the surface conductivity dominates the overall conductivity response of the material. At low salinities, the conductivity of the material can be approximated by the expression of the surface conductivity and therefore we have:

$\sigma_{\infty}^{b} \approx \theta \rho_{g} B C E C$

which is valid only at low salinity (i.e., Du $\gg 1$ ).

While the field induced polarization data are very often acquired in time-domain, laboratory induced polarization data are usually performed in the frequency domain. A general equation can be derived to interpret frequency domain induced polarization measurements. Considering a harmonic external electrical field of the form $\mathbf{E}=\mathbf{E}_{0} \exp$ $(+i \omega t)\left(\omega\right.$ denotes the angular frequency, rad s $\left.^{-1}\right)$ applied to the porous material, the complex conductivity of the volcanic rock is given by (Revil et al., 2017b)

$\sigma^{*}(\omega)=\sigma^{\prime}+i \sigma^{\prime \prime}$

$\sigma^{*}(\omega)=\sigma_{\infty}\left(1-M \int_{0}^{\infty} \frac{h(\tau)}{1+(i \omega \tau)^{1 / 2}} d \tau\right)+i \omega \varepsilon_{\infty}$.
In these equations, $i$ denotes the pure imaginary number and $\varepsilon_{\infty}$ denotes the high frequency permittivity (in $\mathrm{F} \mathrm{m}^{-1}=\mathrm{A} \mathrm{s} \mathrm{V}^{-1} \mathrm{~m}^{-1}$ ). This high frequency permittivity is actually the low frequency part of the Maxwell-Wagner polarization or the dielectric constant of the material in absence of Maxwell-Wagner polarization. The quantity $M$ denotes the chargeability defined in Eqs. (1) and (3), $\tau$ is a time constant (also called a relaxation time since corresponding to a diffusion process, see Figs. 2 and 3), and $h(\tau)$ denotes a (normalized) probability density for the distribution of the (relaxation) time constants of the material and controlling the dispersion of the conductivity curve. While the study of the relaxation times is very interesting in itself, we will focus the present paper only on the conductivity and chargeability of volcanic rocks.

\subsection{Field implementation of IP measurements}

We come back now more specifically to TDIP measurements and the inversion of field data. During a TDIP measurement, a bipolar periodic square current is used to eliminate the effects of spontaneous polarization (self-potential) and background noise. The half cycle of the transmitter waveform $I(t)$ and the corresponding decay curve $\psi(t)$ are shown in Fig. 1 (the complete current waveform includes also a negative box-function to minimize electrode polarization). A series of normally or logarithmically distributed measuring windows $\mathrm{W}_{\mathrm{i}}$ are preset along the decay curve of the secondary voltage values (for instance distributed along a linear or logarithmic time scale). These secondary voltages recorded in the field are integrated in each window $\mathrm{W}_{\mathrm{i}}$ to provide the apparent partial chargeability data (unitless) for a window $\mathrm{W}_{\mathrm{i}}=\left[t_{\mathrm{i}}, t_{\mathrm{i}+1}\right]$ as

$M_{i}=\frac{1}{\psi_{0}\left(t_{i+1}-t_{i}\right)} \int_{t_{i}}^{t_{i+1}} \psi(t) d t$

where $\psi_{0}$ denotes the difference of potential between the measuring electrodes $\mathrm{M}$ and $\mathrm{N}$ before the shutdown of the primary current (primary voltage in steady-state conditions), and $t_{i}$ and $t_{i+1}$ are the start and the end time of the corresponding window (Fig. 1). Typically we use time windows with $t_{i+1}-t_{i}=0.1 \mathrm{~s}$. The partial chargeability $M_{i}$ can make a close approximation to the apparent chargeability $M_{a}$ as long as the window times $t_{i}$ and $t_{i+1}$ are chosen such that $t_{i}<t_{i+1} \ll \tau$ where $\tau$ denotes the main relaxation time of the material for induced polarization (Florsch et al., 2010). This assumption is normally satisfied providing that the measuring time windows are reasonably set in the field. In order to ensure that the condition $t_{i}<t_{i+1} \ll \tau$ is always satisfied, we consider only the partial chargeabilities defined by the first-window $\mathrm{W}_{1}$ to perform our chargeability tomographies.

\subsection{Conductivity and chargeability inversion}

The occurrence of induced polarization impedes the conduction progress (see Figs. 2 and 3 and Seigel, 1959). Indeed, induced polarization is associated with the blocking of electrical charges at some polarization length scales. Then, these charges are not available anymore for the conduction process explaining why conduction depends on time or frequency (Seigel, 1959). The instantaneous conductivity $\sigma_{\infty}$ (all charges are mobile) is related to the DC (direct current) conductivity $\sigma_{0}$ (some charges are immobile because used for the polarization) by the chargeability i.e., $\sigma_{0}=(1-M) \sigma_{\infty}$ (see Eq. (1)). This means that the IP inversion can be performed sequentially in two steps. First, the instantaneous conductivity $\sigma_{\infty}$ is inverted without induced polarization effects. Then, the DC conductivity $\sigma_{0}$ is determined based on the already obtained $\sigma_{\infty}$ and the induced polarization effect described by the partial apparent chargeability $M$ measured on the first window $\mathrm{W}_{1}$ of the secondary voltage decaying curves.

In the usual conditions of TDIP measurements, the displacement current and the electromagnetic induction can be reasonably neglected because of the low frequency transmitter waveform (in the present study 
$T=1 \mathrm{~s}$ ) and the initial time delay (dead time, typically 0.03 to $0.4 \mathrm{~s}$ ) before the measuring window. With the introduction of the instantaneous electrical potential $\psi_{\sigma_{\infty}}$ (in $\mathrm{V}$ ), the Maxwell's equations can be reduced to the following elliptic equation as

$\nabla \cdot\left(\sigma_{\infty} \nabla \psi_{\sigma_{\infty}}\right)=-I \delta\left(\mathbf{r}-\mathbf{r}_{\mathrm{s}}\right)$,

with the boundary condition $\partial \psi_{\sigma_{\infty}} / \partial \hat{\mathbf{n}}=0$ at the earth's surface (the normal component of the electrical field vanishes) and the far field boundary condition $\psi_{\sigma_{\infty}}=0$ (Neumann and second Dirichlet boundary conditions respectively). In these equations, $\hat{\mathbf{n}}$ denotes the unit normal vector to ground surface, $I$ is the injected current (in A), and $\delta\left(\mathbf{r}-\mathbf{r}_{\mathrm{s}}\right.$ ) $\left(\mathrm{m}^{-3}\right.$ ) denotes the 3D delta function where $\mathbf{r}$ and $\mathbf{r}_{\mathrm{s}}$ (in $\mathrm{m}$ ) are the vector position and the position vector of the current source, respectively ( $I$ positive for current injection and negative for current withdrawal from the ground).

Eq. (16) can be solved via the finite element method (forward modeling). During the forward modeling the input model parameters are the subsurface conductivities and the output responses are the potential fields. Once Eq. (16) is solved, the apparent resistivity can be easily derived from the potential difference $\psi_{\mathrm{MN}}$ (either the instantaneous or DC potential $\psi_{\sigma_{0}}$, see Fig. 1) of the two measuring electrodes $\mathrm{M}$ and $\mathrm{N}$ as $\rho_{a}=K \psi_{\mathrm{MN}} / I$ where $K$ denotes the geometrical factor, which can be computed based on the position of the electrodes forming the array ABMN. However, to get the apparent chargeability, we need to solve again an elliptic equation with the instantaneous conductivity $\sigma_{\infty}$ replaced by the expression of the DC conductivity $\sigma_{0}=(1-M) \sigma_{\infty}$, i.e.,

$\nabla \cdot\left(\sigma_{\infty}(1-M) \nabla \psi_{\sigma_{0}}\right)=-I \delta\left(\mathbf{r}-\mathbf{r}_{\mathrm{s}}\right)$

where $\psi_{\sigma_{0}}$ denotes the potential measured at the steady state (Fig. 1). Then the apparent chargeability can be derived using $M_{\mathrm{a}}=\left(\psi_{\sigma_{0}}-\right.$ $\left.\psi_{\sigma_{\infty}}\right) / \psi_{\sigma_{0}}$ (see Fig. 1), where $\psi_{\sigma_{\infty}}$ is the electrical potential obtained by solving Eq. (16). This definition is completely equivalent to the definition used above (see Seigel, 1959).

We discuss from now the inverse problem consisting in retrieving the conductivity and chargeability distributions of the subsurface from the apparent resistivity and chargeability measured at the ground surface with an array of electrodes. Since conductivity and chargeability inversions are both ill-posed problems. Purely fitting the data might lead to a nonphysical result in many circumstances. Tikhonov regularization method is introduced to overcome this difficulty by inverting the data under some constraints (e.g., Tikhonov and Arsenin, 1977; Hansen, 1998). Here we look for the best model vector via minimizing the following objective function $\mathbf{P}^{\lambda}(\mathbf{m})$ :

$\mathbf{P}^{\alpha}(\mathbf{m})=\left\|\mathbf{W}_{d}\left(\mathbf{d}(\mathbf{m})-\mathbf{d}_{\mathrm{obs}}\right)\right\|^{2}+\alpha\left\|\mathbf{W}_{m} \mathbf{m}\right\|^{2}$,

where the model vector $\mathbf{m}$ is the vector corresponding to the logarithm of the instantaneous conductivity $\sigma_{\infty}$ or the intrinsic chargeability $M$ of each cell, the data vector $\mathbf{d}(\mathbf{m})$ denotes the predicted data for the relevant model vector $\mathbf{m}$, the vector $\mathbf{d}_{\text {obs }}$ denotes the logarithm of the observed apparent resistivity data when $\sigma_{\infty}$ is inverted and the apparent chargeability when $M$ is inverted, and $\alpha$ is the regularization parameter that balances the misfit of the data space and the constraint of the model space. Usually the problem is underdetermined. The matrix $\mathbf{W}_{d}$ is related to the data covariance matrix generated from the measurement standard deviations. The matrix $\mathbf{W}_{m}$ is a roughness matrix (we want to penalize the roughness of the tomogram) used to impose constraints on the estimated model. The coefficients in the roughness matrix $\mathbf{W}_{m}$ are built as the approximation of the model gradient. Each cell's coefficient is calculated by the distance weighted differences between the studied cell and its neighbors during the implementation.
An iterative scheme is used to obtain the optimal model vector that minimizes iteratively the objective function $\mathbf{P}^{\alpha}(\mathbf{m})$

$\mathbf{m}_{k+1}=\mathbf{m}_{k}+\zeta_{k} \delta \mathbf{m}$

where $\mathbf{m}_{k}$ and $\mathbf{m}_{k+1}$ are the model vectors at iteration $k$ and at iteration $k+1$, respectively. $\zeta_{k} \in[0,1]$ is the step length of each iteration and $\delta \mathbf{m}$ denotes the perturbation vector in the model space given by

$\delta \mathbf{m}=\left[\mathbf{J}^{T}\left(\mathbf{W}_{d}^{T} \mathbf{W}_{d}\right) \mathbf{J}+\alpha \mathbf{W}_{m}^{T} \mathbf{W}_{m}\right]^{-1}\left[\mathbf{J}^{T}\left(\mathbf{W}_{d}^{T} \mathbf{W}_{d}\right)\left(\mathbf{d}_{o b s}-\mathbf{d}\left(\mathbf{m}_{i}\right)\right)-\alpha \mathbf{W}_{m}^{T} \mathbf{W}_{m} \mathbf{m}_{k}\right]$,

where $\mathbf{J}$ is the sensitivity matrix and $\mathbf{A}^{\mathrm{T}}$ denotes the transpose of the matrix $\mathbf{A}$ ( $\mathbf{A}$ being a general matrix). Since calculating the sensitivity matrix is the most time-intensive part in the optimization, we use the reciprocity method to calculate the first sensitivity matrix and then update the sensitivity matrix using Broyden's method at each iteration (Broyden, 1965). Furthermore, we only assemble the conductivity sensitivity matrix, the chargeability matrix is then deduced from it with some algebraic operations resulting in the following relationship

$$
\frac{\partial d_{i}}{\partial \log M_{j}}=-\frac{M_{j}}{1-M_{j}} \frac{\psi_{\sigma_{\infty} \mid i}}{\left(\psi_{\sigma_{0} \mid i}\right)^{2}} \frac{\partial \psi_{\sigma_{\infty} \mid i}}{\partial \log \sigma_{0 \mid j}} .
$$

In Eq. (21) $\partial d_{i} / \partial \log M_{j}$ denotes the chargeability sensitivity matrix and $\partial \Psi_{\sigma_{\infty} i} / \partial \log \sigma_{0 \mid j}$ is the conductivity sensitivity matrix associated to $\sigma_{0}=\sigma_{\infty}\left(1-M_{j}\right)$. During the iteration, the choice of step size $\zeta_{k}$ is based on a line search to make the objective function decreasing while the regularization parameter $\alpha$ is started with a high value and, then, we use a cooling approach to decrease its value during the inversion process. This process is considered to have converged when the data misfit reaches a root mean square (RMS) error $<5 \%$ and the last model is taken as the inverted model. Benchmark of the resistivity and chargeability inversion method on synthetic and true field data has already been performed in Qi et al. (2018) and will not be repeated here. Note that the resolution of the induced polarization tomography is controlled by the same parameters than for electrical conductivity tomography.

\section{Petrophysical investigations}

\subsection{Material and methods}

The measurements are performed on six cubic samples (sample length varies between 2.5 and $6.5 \mathrm{~cm}$ ) from Krafla (Fig. 4). The samples are shown in Fig. 5. The rock samples were initially saturated with a low salinity $\mathrm{NaCl}$ solution in a vacuum chamber for $24 \mathrm{~h}$ and therefore $\theta=\phi$, i.e., the water content reduced to the porosity. We use a high grade dehydrated $\mathrm{NaCl}$ salt and demineralized water to prepare the brines. Then, the core samples are left two weeks in the brine solution in a closed container, and their conductivity is measured until the value stabilizes. Afterwards, the samples are removed from their containers for complex conductivity measurements. We use a frequency range from $10 \mathrm{mHz}$ to $45 \mathrm{kHz}$. The complex conductivity measurements are performed using a four electrodes technique (Fig. 5a, see for instance Herman, 2001; Michot et al., 2016) and the high-precision impedance analyzer developed by Zimmermann et al. (2008, Fig. 5b). Two current electrodes (A and B) are placed at the end faces as current electrodes and two other electrodes are used on the side of the cylindrical cores as voltage electrodes ( $\mathrm{M}$ and $\mathrm{N}$ ). The current ( $\mathrm{A}$ and $\mathrm{B}$ ) and voltage ( $\mathrm{M}$ and $\mathrm{N}$ ) electrodes are self-adhesive non-polarizing $\mathrm{Ag}-\mathrm{AgCl}$ Biomedical electrodes (Revil et al., 2018) used with the sample holder. We also run the experiments using superconductive carbon film electrodes as the current electrodes and the same non-polarizing $\mathrm{Ag}-\mathrm{AgCl}$ Biomedical electrodes used as the voltage electrodes. We kept the same voltage 


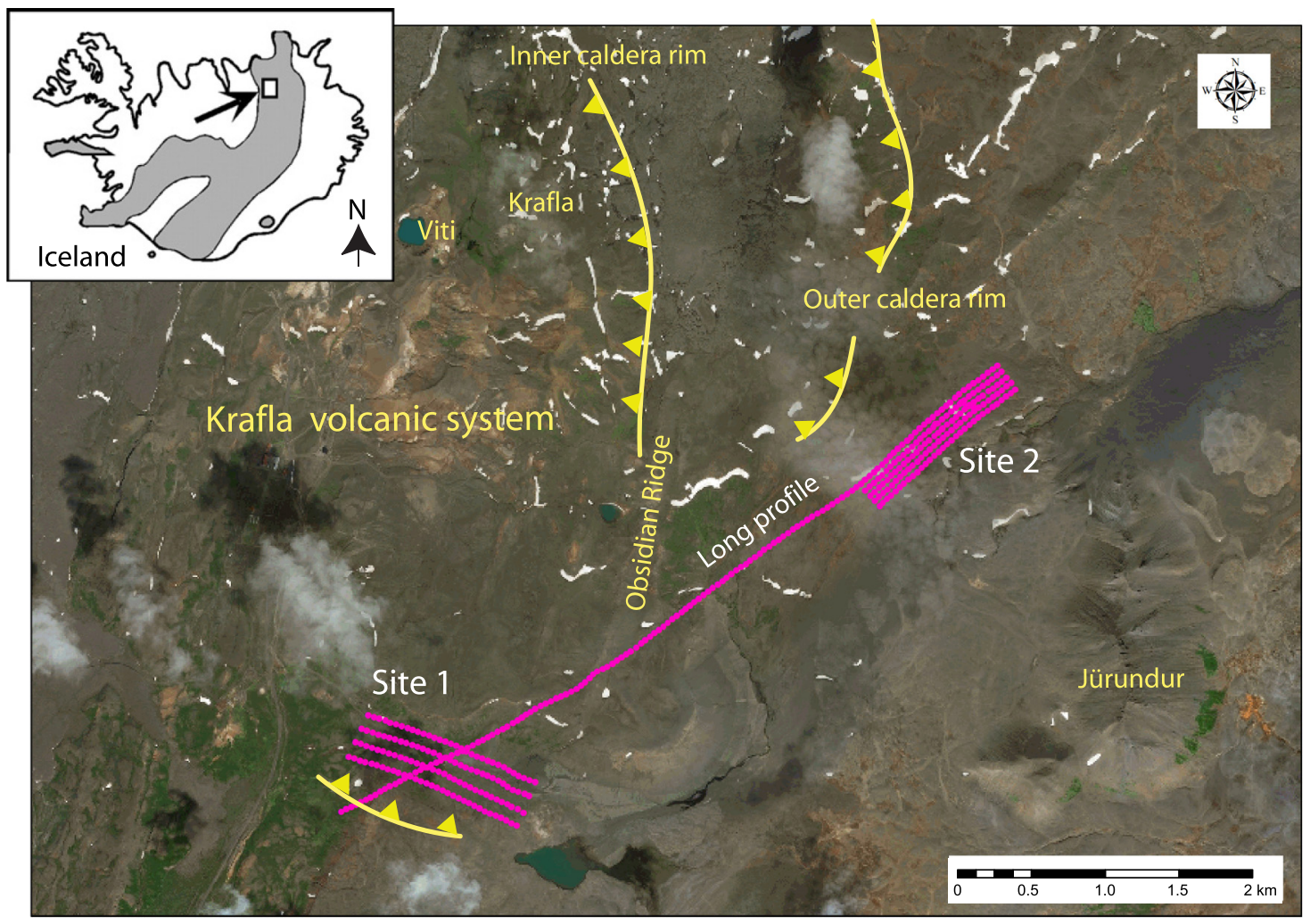

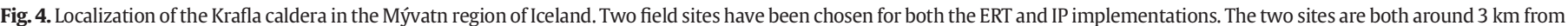

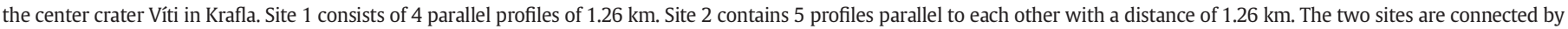

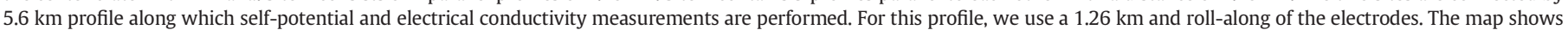

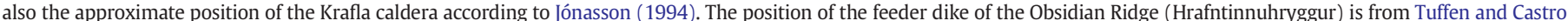
(2009). Insert: position of Krafla in Iceland. The grey areas correspond to the Northern Volcanic Zone (NVZ), Eastern Volcanic Zone (EVZ), and Western Volcanic Zone (WVZ).

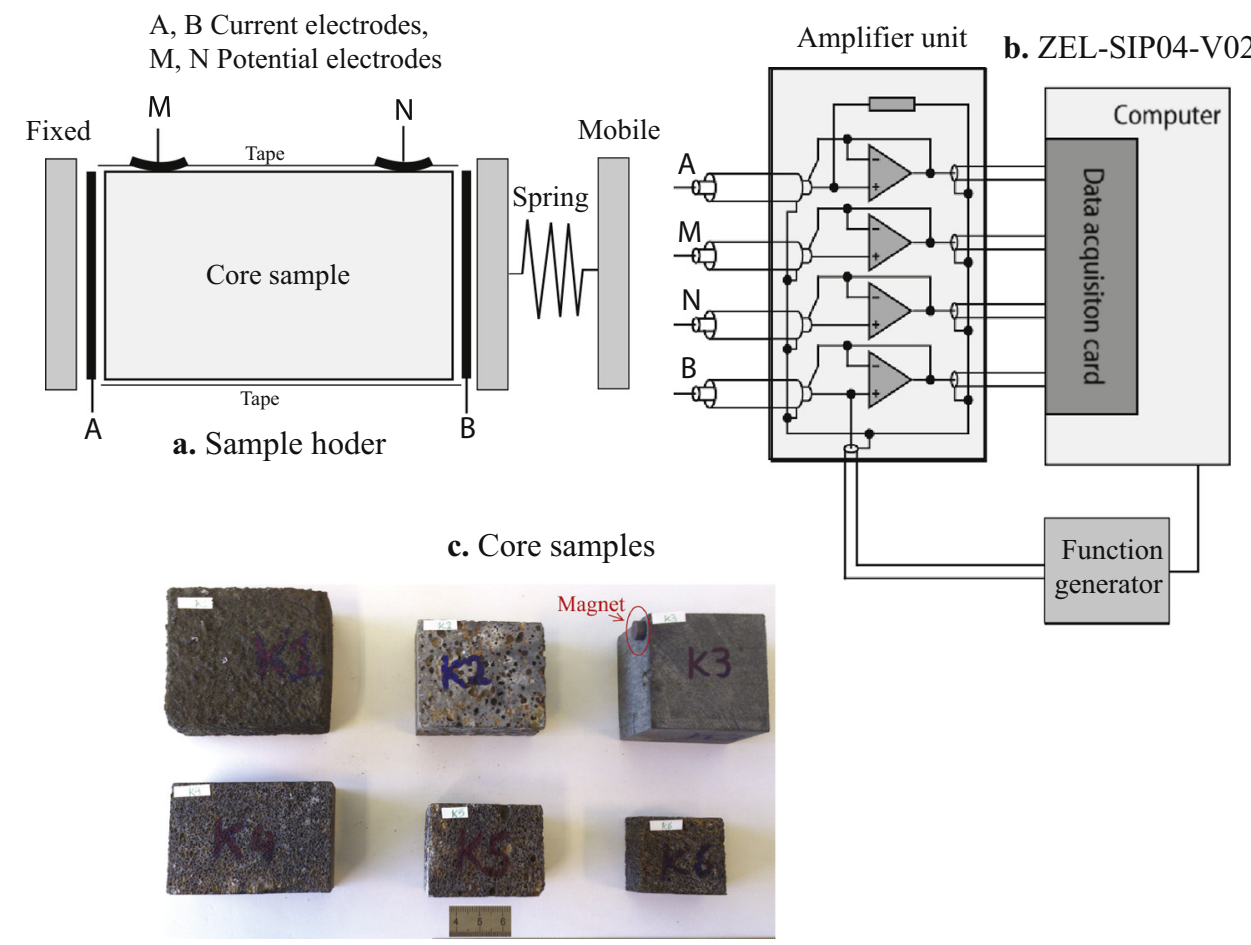

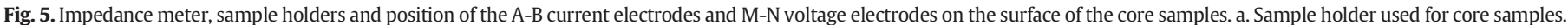

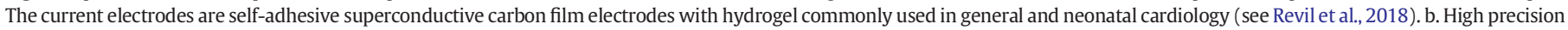

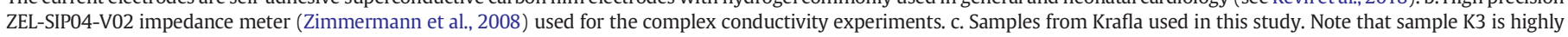
magnetized. 

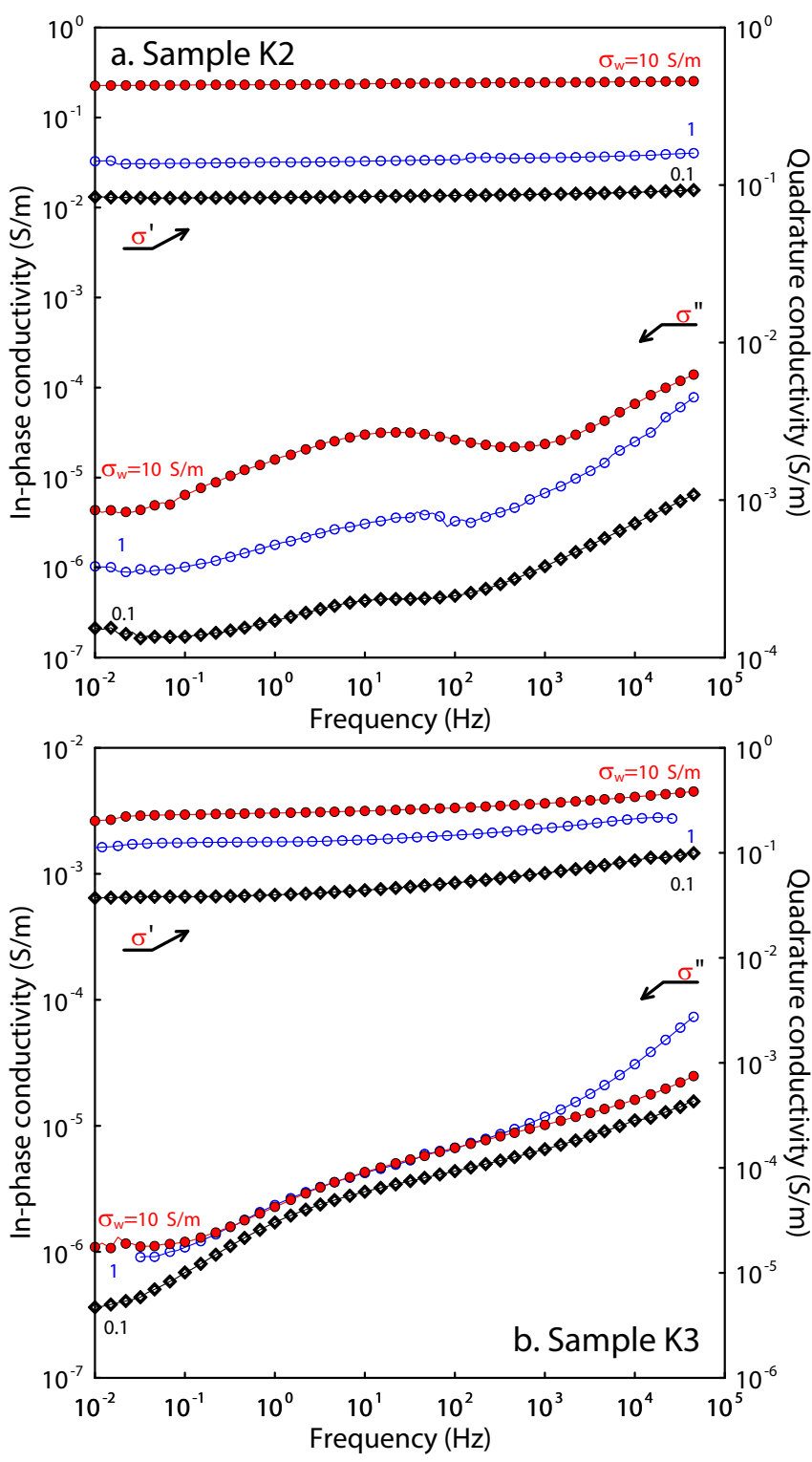

Fig. 6. Spectral induced polarization data (in-phase conductivity $\sigma^{\prime}$ and quadrature conductivity $\sigma^{\prime \prime}$ ) for two volcanic samples from Iceland volcano Krafla in the frequency range $10 \mathrm{mHz}-45 \mathrm{kHz}$. a. In-phase and quadrature conductivities spectra of core sample K2. b. In-phase and quadrature conductivities spectra K3. The induced polarization measurements are performed at three pore-water conductivities $\left(0.1,1\right.$ and $10 \mathrm{~S} \mathrm{~m}^{-1}, \mathrm{NaCl}$, $\left.25^{\circ} \mathrm{C}\right)$.

for the current electrodes during the two types of experiments. We did not observe small noisy positive phases when we used the four $\mathrm{Ag}-\mathrm{AgCl}$ Biomedical electrodes. This is an important metrological quality control when the size of the core sample is small.
Table 2

Relevant petrophysical of the 15 unaltered core samples from Kilauea volcano in Hawai (unpublished results). The quantity $\rho_{g}$ denotes the grain density $\left(\mathrm{kg} \mathrm{m}^{-3}\right), \phi$ the connected porosity (dimensionless), $F$ the electrical (intrinsic) formation factor (dimensionless), CEC (expressed in meq/100 g) denotes the cation exchange capacity, and $\sigma^{\prime \prime}$ (in $\mathrm{S} \mathrm{m}{ }^{-1}$ ) denotes the quadrature conductivity at $1 \mathrm{~Hz}$ and pore water conductivity $0.15 \mathrm{~S} \mathrm{~m}^{-1}(\mathrm{NaCl})$.

\begin{tabular}{lllccccl}
\hline Sample & $\begin{array}{l}\phi \\
(-)\end{array}$ & $\begin{array}{l}\rho_{g} \\
\left(\mathrm{~kg} \mathrm{~m}^{-3}\right)\end{array}$ & $\begin{array}{l}F \\
(-)\end{array}$ & $\begin{array}{l}\text { CEC } \\
(\mathrm{meq} / 100 \mathrm{~g})\end{array}$ & $\begin{array}{l}\sigma_{\mathrm{S}} \\
\left(10^{-4} \mathrm{~S} S\right. \\
\left.\mathrm{m}^{-1}\right)\end{array}$ & $\begin{array}{l}\sigma^{\prime \prime} \\
\left(10^{-5} \mathrm{~S}\right. \\
\left.\mathrm{m}^{-1}\right)\end{array}$ & Type \\
\hline ECH 01 & 0.38 & 2712 & 11 & 0.937 & 208.0 & 5.2 & Lava flow \\
ECH 02 & 0.43 & 2885 & 6 & 0.726 & 31.0 & 6.4 & Lava flow \\
ECH 03 & 0.29 & 2744 & 10 & 0.426 & 31.6 & 4.6 & Lava flow \\
ECH 04 & 0.40 & 3689 & 7 & 0.512 & 11.3 & 3.1 & Lava flow \\
ECH 05 & 0.62 & 3679 & 7 & 3.326 & 94.1 & 12.3 & Lithics \\
ECH 06 & 0.40 & 3325 & 9 & 0.979 & 13.3 & 3.2 & Projections \\
ECH 07 & 0.39 & 3304 & 10 & 1.021 & 49.1 & 4.8 & Lava flow \\
ECH 08 & 0.56 & 3834 & 7 & 0.766 & 2.1 & 3.5 & Lava flow \\
ECH 09 & 0.48 & 3686 & 10 & 1.062 & 22.7 & 5.5 & Lava flow \\
ECH 10 & 0.52 & 3733 & 7 & 0.594 & 16.0 & 5.6 & Lava flow \\
& & & & & & & Lava spatter \\
ECH 11 & 0.55 & 3792 & 7 & 0.594 & 4.2 & 4.5 & cone \\
ECH 12 & 0.48 & 3852 & 7 & 1.062 & 30.3 & 5.4 & Lava flow \\
ECH 13 & 0.40 & 2872 & 11 & 1.061 & 21.8 & 3.1 & Lithics \\
& & & & & & & Various \\
Lac 01 & 0.65 & 3661 & 8 & 1.614 & 123.1 & 7.3 & projections \\
Lac 02 & 0.67 & 3505 & 4 & 0.552 & -17.6 & 4.4 & Pelee's hair \\
\hline
\end{tabular}

The complex conductivity spectra $\sigma^{\prime}$ and $\sigma^{\prime \prime}$ are shown in Fig. 6 for two core samples (K2 and K3). We repeated the same procedure for three pore water conductivities $0.1,1.0$, and $10 \mathrm{~S} \mathrm{~m}^{-1}$. The petrophysical properties are reported in Table 1 and are contrasted with 15 other samples from Kilauea volcano (see Table 2 ). The (connected) porosity and density of the mineral phase were determined using the volume and mass of the dry and saturated samples. The Cation Exchange Capacity (CEC) measurements were obtained using the cobalt hexamine chloride method (Ciesielski and Sterckemann, 1997 and Aran et al., 2008). We also used six powder samples for the size core samples in order to estimate their specific surface area (in $\mathrm{m}^{2} \mathrm{~g}^{-1}$ ) using the BET nitrogen adsorption technique (Brunauer et al., 1938, see also Revil et al., 2017a, for volcanic rocks). The formation factor $F$ and surface conductivity $\sigma_{S}$ are determined by plotting the in-phase conductivity $\sigma^{\prime}$ of the core sample versus the conductivity of the brine $\sigma_{w}$ and fitting the data with $\sigma^{\prime}=$ $\sigma_{w} / F+\sigma_{S}$ (see Fig. 7). We also measured the magnetic susceptibility of six powder samples (Table 1) using Bartington MS2E sensor and MS2 Magnetic Susceptibility Meter (Calibration accuracy 2\% and Resolution to $2 \times 10^{-6} \mathrm{SI}$ ). Before the measurements, the calibration process of sensor done. Small cylindrical sample holders $(10 \mathrm{~mm}$ in both of length and diameter) were filled with our samples in powders.

Samples K2 and K3 were also the subject of complex conductivity measurements at temperatures between 5 and $50{ }^{\circ} \mathrm{C}(\mathrm{NaCl}$, conductivity of $3.3 \times 10^{-3} \mathrm{~S} \mathrm{~m}^{-1}$ at $25^{\circ} \mathrm{C}$ ). This was done to investigate the effect of the temperature on the quadrature conductivity (or normalized chargeability) of the complex conductivity of volcanic rock samples.

Table 1

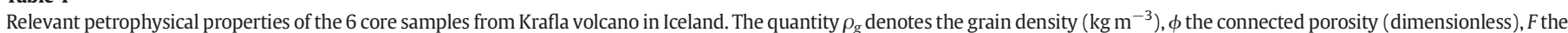

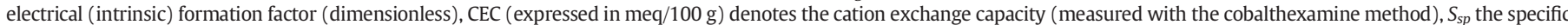
surface area (measured with the BET technique), and $\sigma^{\prime \prime}\left(\right.$ in S m${ }^{-1}$ ) denotes the quadrature conductivity at $1 \mathrm{~Hz}$ and at a pore water conductivity $0.1 \mathrm{~S} \mathrm{~m}^{-1}$ (NaCl).

\begin{tabular}{|c|c|c|c|c|c|c|c|c|}
\hline Sample & $\begin{array}{l}\phi \\
(-)\end{array}$ & $\begin{array}{l}\rho_{g} \\
\left(\mathrm{~kg} \mathrm{~m}^{-3}\right)\end{array}$ & $\begin{array}{l}F \\
(-)\end{array}$ & $\begin{array}{l}\text { CEC } \\
\text { (meq/100 g) }\end{array}$ & $\begin{array}{l}S_{s p} \\
\left(\mathrm{~m}^{2} \mathrm{~g}^{-1}\right)\end{array}$ & $\begin{array}{l}\sigma_{S} \\
\left(10^{-4} \mathrm{~S} \mathrm{~m}^{-1}\right)\end{array}$ & $\begin{array}{l}\sigma^{\prime \prime} \\
\left(10^{-5} \mathrm{~S} \mathrm{~m}^{-1}\right)\end{array}$ & $\begin{array}{l}\text { Magnetic susceptibility } \\
\left(10^{-3} \mathrm{SI}\right)\end{array}$ \\
\hline K1 & 0.39 & 2640 & 9 & 11.398 & $30.74 \pm 0.45$ & 46.7 & 6.5 & 0.95 \\
\hline K2 & 0.33 & 2860 & 44 & 3.699 & $10.06 \pm 0.16$ & 106.5 & 17.2 & 3.94 \\
\hline K3 & 0.03 & 2970 & 3857 & 11.772 & $5.87 \pm 0.09$ & 8.8 & 3.0 & 13.93 \\
\hline K4 & 0.45 & 2740 & 21 & 3.183 & $7.73 \pm 0.14$ & 2.5 & 4.0 & 3.04 \\
\hline K5 & 0.49 & 2830 & 25 & 3.140 & $6.35 \pm 0.10$ & 17.3 & 14.2 & 3.88 \\
\hline K6 & 0.48 & 2980 & 17 & 3.087 & $10.13 \pm 0.14$ & 50.7 & 3.8 & 4.80 \\
\hline
\end{tabular}




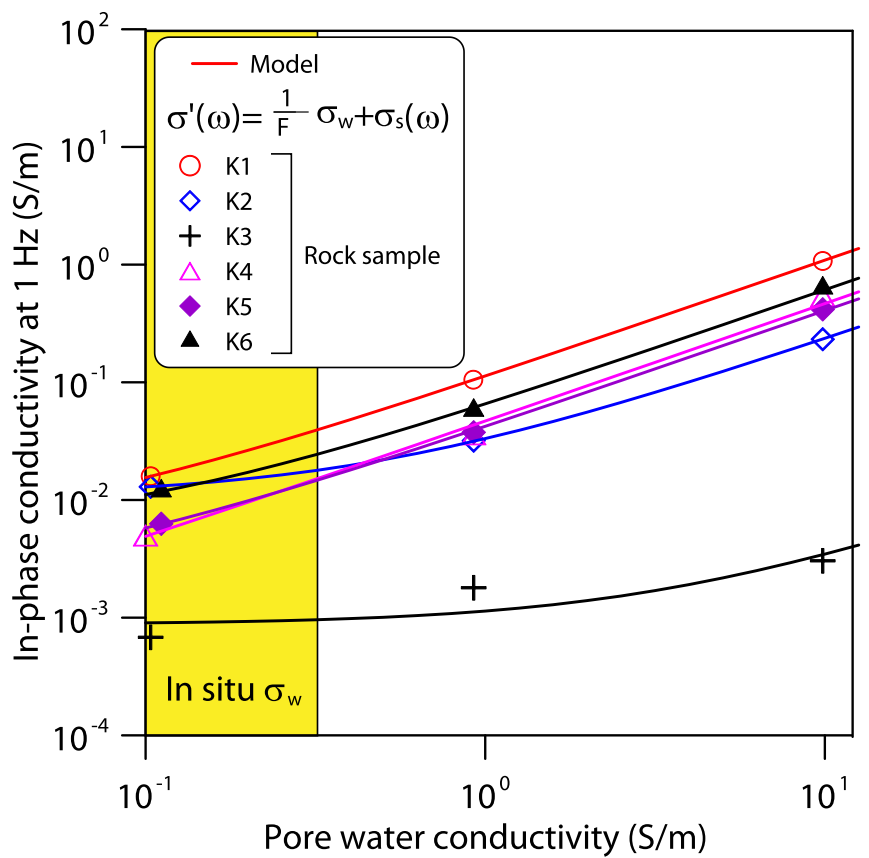

Fig. 7. Relationship between the in-phase conductivity $\sigma^{\prime}$ and pore water conductivity $\sigma_{w}$ for three core samples from Krafla. The conductivity of the rock sample (at $1 \mathrm{~Hz}$ ) is plotted as a function of the conductivity of the pore water $\sigma_{w}$ at three pore water salinities $(0.1,1$ and $10 \mathrm{~S} \mathrm{~m}^{-1}, \mathrm{NaCl}, 25^{\circ} \mathrm{C}$ ). The values of the formation factor $F$ and surface conductivity $\sigma_{\mathrm{s}}$ are obtained by fitting the data with the linear conductivity equation (plain lines). The resulting values are provided in Table 1 . The yellow area corresponds to the in situ pore water conductivities at Krafla (see Appendix A and Fridleifsson et al., 2006, 0.1 to $0.3 \mathrm{~S} \mathrm{~m}^{-1}$ at $25{ }^{\circ} \mathrm{C}$ ). (For interpretation of the references to color in this figure legend, the reader is referred to the web version of this article.)

\subsection{Results}

In Fig. 7, we also report the in situ pore water conductivity at $25^{\circ} \mathrm{C}$ for Krafla (see discussion in Appendix A). We see that surface conductivity is important but that the bulk pore water contribution cannot be neglected either. Fig. 8a shows the formation factor versus the porosity for the data set from the present study plus some additional data from Krafla and some basaltic core samples from Hawaii. The porosity (or cementation) exponent $m$ entering Archie's law is $m=2.57 \pm 0.10$, a quite high value that is consistent with the study of Flóvenz et al. (2005).

Fig. $8 \mathrm{~b}$ shows that the surface conductivity in the range $(3-110)$ $\times 10^{-4} \mathrm{~S} \mathrm{~m}^{-1}$ is controlled by the ratio between the cation exchange capacity (CEC) and tortuosity (given by the product $F \phi$ ). Similarly, the quadrature conductivity is also grossly controlled by the ratio between the CEC and the product $F \phi=\phi^{1-m}$ (Fig. 9). These findings are in agreement with Eqs. (7) and (8). Our result for surface conductivity are also in agreement with those from Flóvenz et al. (2005) who found that the unaltered samples from Krafla have a surface conductivity on the order of $5 \times 10^{-4} \mathrm{~S} \mathrm{~m}^{-1}$

The relationship between the quadrature conductivity and the surface conductivity is a pretty important relationship since it means that if such a relationship exists, surface conductivity can be predicted directly from the measurement of the quadrature conductivity. In this case it means that bulk and surface conductivity can be separated in field studies. Fig. 10 shows that quadrature conductivity and surface conductivity are roughly proportional to each other. Revil et al. (2017a, 2017b) established a direct linear relationship between two polarization parameters, namely the normalized chargeability (usually determined with time domain induced polarization) and the quadrature conductivity (usually determined using frequency-domain induced polarization data). This relationship is also checked in the present study (see Fig. 11) and can be used with a pretty high level of confidence.
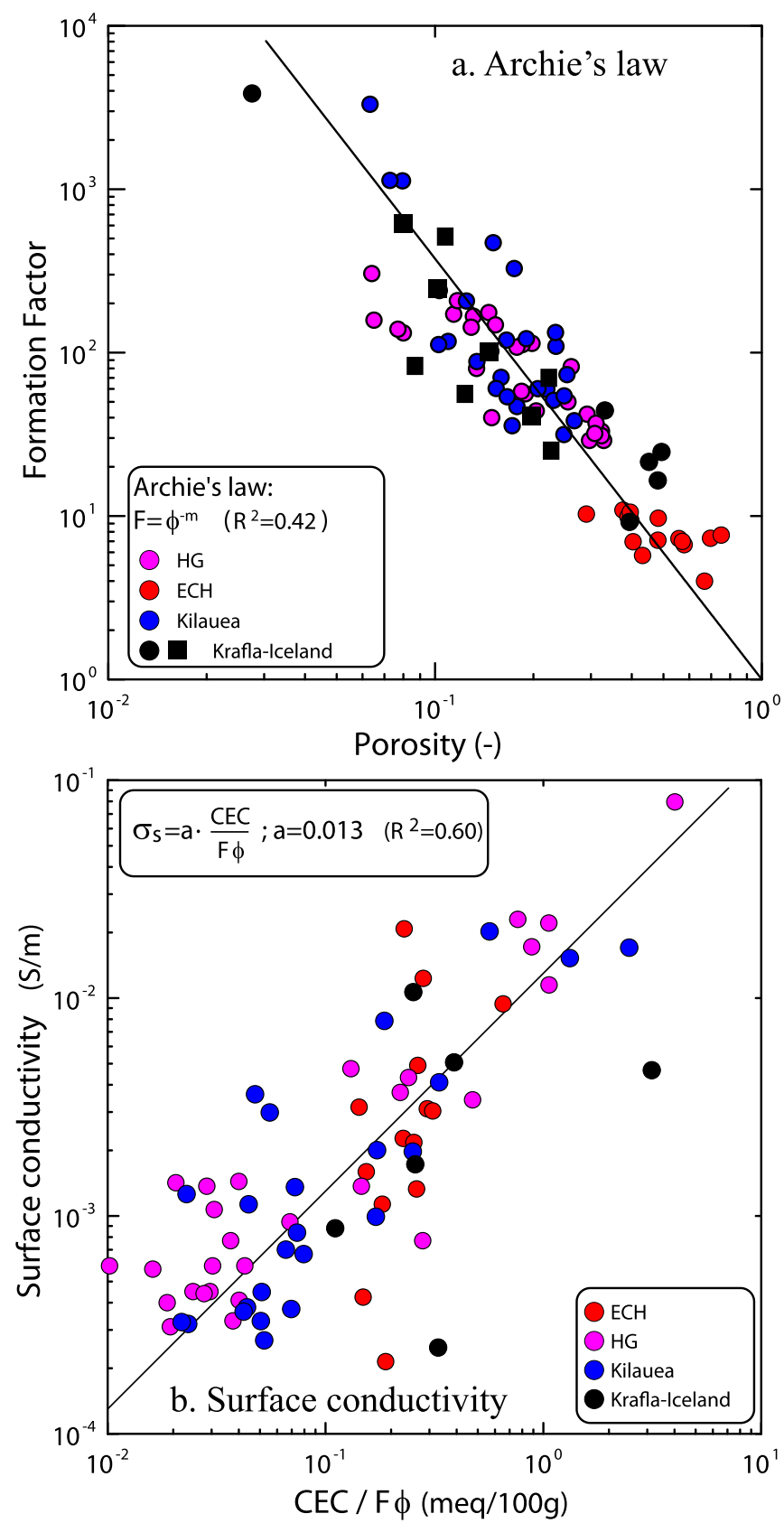

Fig. 8. Formation factor and surface conductivity. a. The intrinsic formation factor $F$ versus the connected porosity $\phi$ for the volcanic rocks of Hawaii, samples ECH and HG (Revil et al., 2017a, 2017b) and 10 core sample from Krafla in Iceland (6 from this paper, filled circles and the others from the study of Flóvenz et al., 2005, filled squares). We fit the complete data set with Archie's law $F=\phi^{-m}$, where the fitted cementation exponent is $m=$ $2.57 \pm 0.10$ (dimensionless). b. Surface conductivity (in $\mathrm{S} \mathrm{m}^{-1}$ ) versus the normalized cation exchange capacity (CEC/F $\phi$ where the CEC is expressed in meq/100 g, $F$ the formation factor, and $\phi$ the connected porosity). Note $1 \mathrm{meq} /(100 \mathrm{~g})=963.2 \mathrm{C} \mathrm{kg}^{-1}$ in SI units. The scatter in this figure could come from the fact that the $\mathrm{pH}$ was not buffered during the CEC measurements.

The relationship between the normalized chargeability and the surface conductivity is shown in Fig. 12. In Fig. 12a, we first determine qualitatively the magnetite content using a magnet and a fraction of the core sample reduced in fine powder (see also Table 1 where the magnetic susceptibility of the core samples has been measured). We found that some samples are very rich in magnetite (K3, K4, and $\mathrm{K} 5$ ) while the others, characterized by higher CEC values, are poor in magnetite. Usually, we expect magnetite to be present in the fresh samples and destroyed by alteration in the most altered samples. For the samples 


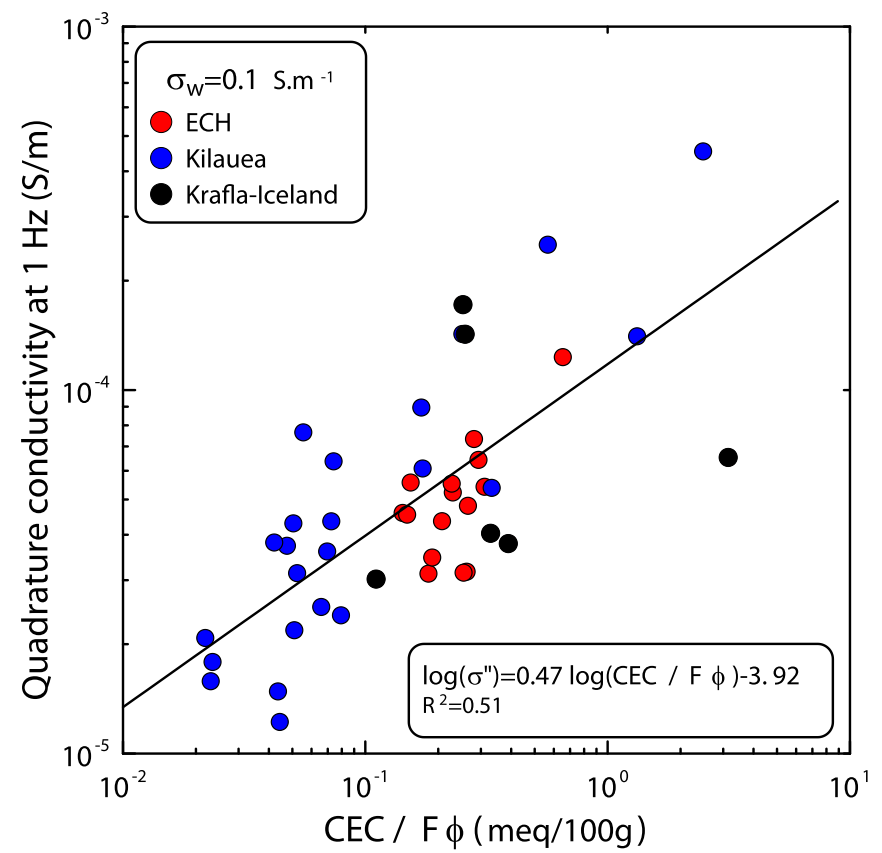

Fig. 9. Relationship between the quadrature conductivity (at a pore-water conductivity of approximately $0.1 \mathrm{~S} \mathrm{~m}^{-1}$ and taken at $1 \mathrm{~Hz}$ ) and normalized CEC (i.e., the CEC divided by the tortuosity of the bulk pore space). The tortuosity of the bulk pore space is determined as the product of the (intrinsic) formation factor $F$ by the (connected) porosity $\phi$ $\left(1 \mathrm{meq} /(100 \mathrm{~g})=963.2 \mathrm{C} \mathrm{kg}^{-1}\right)$.

characterized by the higher $\mathrm{CEC}$, the normalized chargeability data (determined here between $1 \mathrm{~Hz}$ and $1 \mathrm{kHz}$ as the difference in the in-phase conductivity, $0.1 \mathrm{~S} \mathrm{~m}^{-1}, \mathrm{NaCl}, 25^{\circ} \mathrm{C}$ ) versus the surface conductivity can be fitted with a straight line. The fit with such a linear model between the normalized chargeability and the surface conductivity leads to $R=$ 0.11 , close to the value determined in previous studies (typically $R=$ 0.08, see Revil et al., 2017a, 2017b).

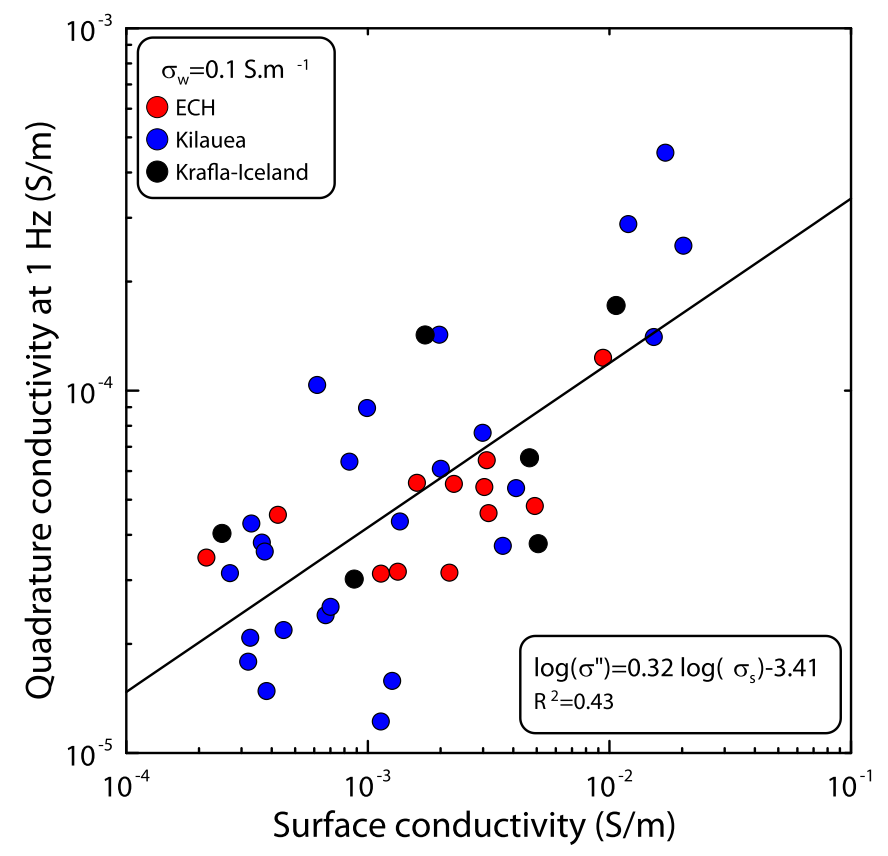

Fig. 10. Quadrature conductivity versus surface conductivity (at a pore-water conductivity of approximately $0.1 \mathrm{~S} \mathrm{~m}^{-1}$ and taken at $1 \mathrm{~Hz}$ ) for volcanic rocks. Note that this trend is independent of the value of the formation factor and electrical tortuosity, saturation, and temperature.

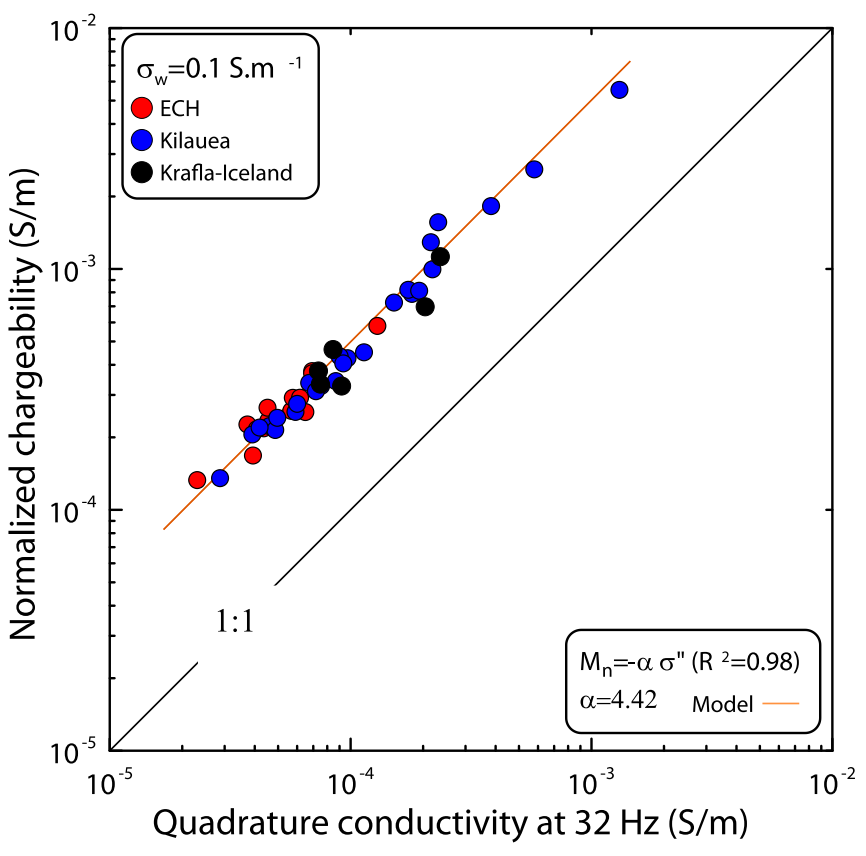

Fig. 11. Relationship between normalized chargeability (determined between $1 \mathrm{~Hz}$ and $1 \mathrm{kHz}$ as the difference in the in-phase conductivity) and the quadrature conductivity (at the geometric mean frequency of $32 \mathrm{~Hz}$ ) for the volcanic samples at $0.1 \mathrm{~S} \mathrm{~m}^{-1}(\mathrm{NaCl}$ $25^{\circ} \mathrm{C}$ ). The plain orange line corresponds to the best fit of the data using a linear model between the normalized chargeability and the quadrature conductivity as prescribed by the theory. (For interpretation of the references to color in this figure legend, the reader is referred to the web version of this article.)

Complex conductivity spectra performed at different temperatures are shown in Fig. 13. The quadrature conductivity versus temperature at $10 \mathrm{~Hz}$ are shown in Fig. 14. The data can be very well fitted with an Arrhenius equation

$\sigma^{\prime \prime}(T)=\sigma^{\prime \prime}\left(T_{0}\right) \exp \left[-\frac{E_{a}}{k_{b} N}\left(\frac{1}{T}-\frac{1}{T_{0}}\right)\right]$

where $T$ and $T_{0}$ are expressed in degree Kelvin $(\mathrm{K})\left(T_{0}=298 \mathrm{~K}\right.$, i.e., 25 ${ }^{\circ} \mathrm{C}$ ), the product $k_{b} N$ (product of the Boltzmann constant by the Avogadro number $N=6.02 \times 10^{23} \mathrm{~mol}^{-1}$ ) denotes the universal gas constant $\left(k_{b} N=8.314 \mathrm{~J} \mathrm{~mol}^{-1} \mathrm{~K}^{-1}\right)$, and $E_{a}$ denotes the activation energy. According to Fig. 14, we obtain an activation energy $E_{a}$ in the rage $16-19 \mathrm{~kJ} \mathrm{~mol}^{-1}$. The activation energy of $16 \mathrm{~kJ} \mathrm{~mol}^{-1}$ is used in Appendix A to derive the porosity and cation exchange capacity from induced polarization surveys. While not shown here, the in-phase conductivity data can also be fitted with an Arrhenius equation activation energy of $15-16 \mathrm{~kJ} \mathrm{~mol}^{-1}$.

\section{Geophysical surveys}

\subsection{D electrical resistivity and induced polarization surveys}

The induced polarization and electrical conductivity surveys were performed in August and September 2017. Two field sites (termed Sites 1 and 2) were chosen to implement our field work (see positions in Fig. 4). These two sites are both located about $3 \mathrm{~km}$ from the Krafla's central crater Víti and they are separated by a distance of roughly $3 \mathrm{~km}$ in an area where there are no obvious geothermal manifestations at the ground surface. Site 1 consists of 4 parallel profiles separated by a distance of $100 \mathrm{~m}$. Each profile (1240 m long) consists of 32 electrodes with a separation of $40 \mathrm{~m}$. Site 2 consists of 5 parallel profiles with a closer profile interval of $50 \mathrm{~m}$. Each profile also consists of 32 electrodes with an electrodes separation of $40 \mathrm{~m}$. For each profile, we used two 

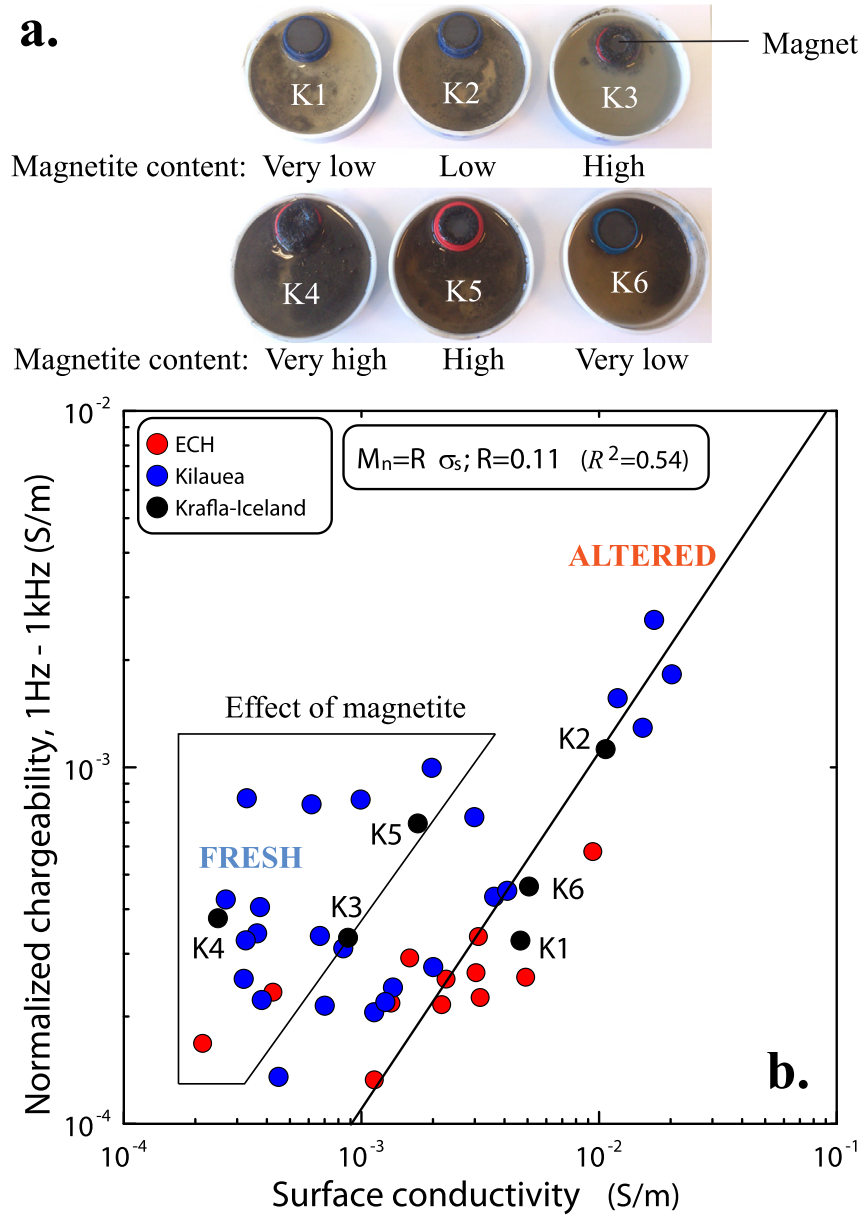

Fig. 12. Relationship between normalized chargeability and the surface conductivity for the volcanic samples. a. Qualitative estimation of the magnetite content using a magnet and a fraction of the core sample reduced in fine powder. b. Normalized chargeability (determined between $1 \mathrm{~Hz}$ and $1 \mathrm{kHz}$ as the difference in the in-phase conductivity, $0.1 \mathrm{~S} \mathrm{~m}^{-1}, \mathrm{NaCl}, 25^{\circ} \mathrm{C}$ ) versus surface conductivity. The plain line corresponds to the best fit of the data using a linear model between the normalized chargeability and the surface conductivity. The measured slope leads to the following value of the dimensionless number $R=0.11$. Sample K3 is characterized by a very high magnetic susceptibility and $\mathrm{K} 1$ by a very low magnetic susceptibility (Table 1 ).

cables separated by a distance of $5 \mathrm{~m}$, one for the injection of the electrical current and one for the voltage measurements.

The measurements were carried out using an ABEM SAS4000 instrument ( 4 channels resistivity meter) and an ABEM LS instrument. Multigradient array measurements were adopted for the collection of apparent resistivity and apparent chargeability data at the two sites. The choice of multi-gradient configuration was motivated by the fact that we separated the cables for the current injection from the cables used for the voltage measurements (see Dahlin et al., 2002). In other words, the electrodes used for injecting the current are different from those used for measuring the induced voltages. This method is used for acquiring high quality time-domain IP data as discussed below. This electrode separation was done in order to reduce the electromagnetic coupling effects especially between the wires contained in the same cable (there are 32 wires in the same cable with the equipment we used). Furthermore, current electrode polarization can last several minutes with high contact resistances and these electrodes should not be used as voltage electrode during this time. During the measurements, electrode coordinates were obtained using a real-time kinematic Global Positioning System (GPS). Electrode elevations were recovered using a linear interpolation scheme and a $1 \mathrm{~m}$ resolution Digital Elevation Model (DEM). Topographic change at Site 1 is $81 \mathrm{~m}$ with the maximum elevation of $532 \mathrm{~m}$ and the minimum $451 \mathrm{~m}$ while the change is $51 \mathrm{~m}$ for the Site 2 where the maximum elevation is $607 \mathrm{~m}$ and the minimum is $556 \mathrm{~m}$. Finally a total of 920 apparent resistivities and also 920 apparent chargeabilities were measured for Site 1 and 1179 apparent resistivities and apparent chargeabilities data were acquired for Site 2 .

\subsection{Long $2 \mathrm{D}$ electrical resistivity survey}

In addition, a $5.6 \mathrm{~km}$-long profile was done to connect the two areas with 149 stainless steel electrodes and an electrode spacing of $40 \mathrm{~m}$. A total 1221 apparent resistivities data were collected for this long profile using a Wenner-alpha array to insure a good signal-to-noise ratio (protocol WEN64XL using the UP-roll along approach). A minimum of 3 stacks and a maximum of 8 stacks (with a target standard deviation of $6 \%$ ) were used for this profile. The measurements were done with an ABEM SAS4000. This profile was made to connect Sites 1 and 2 and to cross the obsidian ridge also called Hrafntinnuhryggur. Hrafntinnuhryggur corresponds to a rhyolitic fissure eruption beneath thin ice/firn ( $<55 \mathrm{~m}$ ) (Tuffen and Castro, 2009). Our goal was also to discover its feeder dike. We were also looking for the geometry of the clay cap and the position of the inner caldera rim of Krafla. In addition, a self-potential survey was carried out at the same position than the electrodes used for the electrical resistivity survey. We used Petiau non-polarizable electrodes known for their small temperature drift and a high precision voltmeter (internal impedance $100 \mathrm{M} \Omega$, sensitivity $0.1 \mathrm{mV}$, see Petiau, 2000).

\section{Results}

\section{1. $3 D$ surveys}

Unstructured tetrahedral meshes were used to discretize the geometrical domain in our forward modeling and inversion. To accurately yet also efficiently solve the forward modeling, the mesh is refined close to the electrodes. The sensitive core regions are therefore characterized by a finer mesh than the other regions that are far from the electrodes. Site 1 was discretized into 86,460 elements (Fig. 15) accounting for the topography. These meshes were fixed during the inversion and the same meshes were used for resistivity and chargeability inversions.

3D multi-slices of the inverted conductivity tomography at Site 1 are shown in Fig. 16, which represents a stratified characteristic that the magnitude increases from the resistive upper layers to the conductive bottom layers. A similar characteristic can also be seen in Fig. 17 of the normalized chargeability tomography where bottom layers have more than two orders of normalized chargeability than the overlays. While for the chargeability tomography in Fig. 18, although stratified features can still be seen, the intrinsic chargeability magnitude is very small across the whole domain which ranges from 0.01 to 0.04 . When these inverted physical properties are shown in 2D slices (from Figs. 19 to 21 ), these patterns can be more obviously seen.

Site 2 data were also inverted with a mesh consisting of 85,074 elements (Fig. 22). Inverted conductivities, normalized chargeabilities and chargeabilities (Figs. 23 to 25) all represent horizontally layered characteristics with respect to the surface tomography. 2D slices again validate this layered feature and also the magnitude differences (from Figs. 26 to 28).

These data are consistent with the general electrical conductivity structure discussed by Árnason et al. (2010). It consists generally of an upper low conductivity body corresponding to unaltered basalts. This layer overlies a conductive layer at variable depths, from near surface to a depth of few hundred meters. This layer corresponds to the smectite-rich clay-cap (rock alteration zone) with alteration formed in the temperature range of $100-240^{\circ} \mathrm{C}$. This corresponds to the impermeable clay cap in geothermal systems. The top of this layer is where the low hydrothermal alteration occurs (at temperature $50-100{ }^{\circ} \mathrm{C}$ ) and appears as the beginning of smectite-zeolite zone. From few hundred meters to a depth of $2.5 \mathrm{~km}$, a lower conductive layer is observed. The 

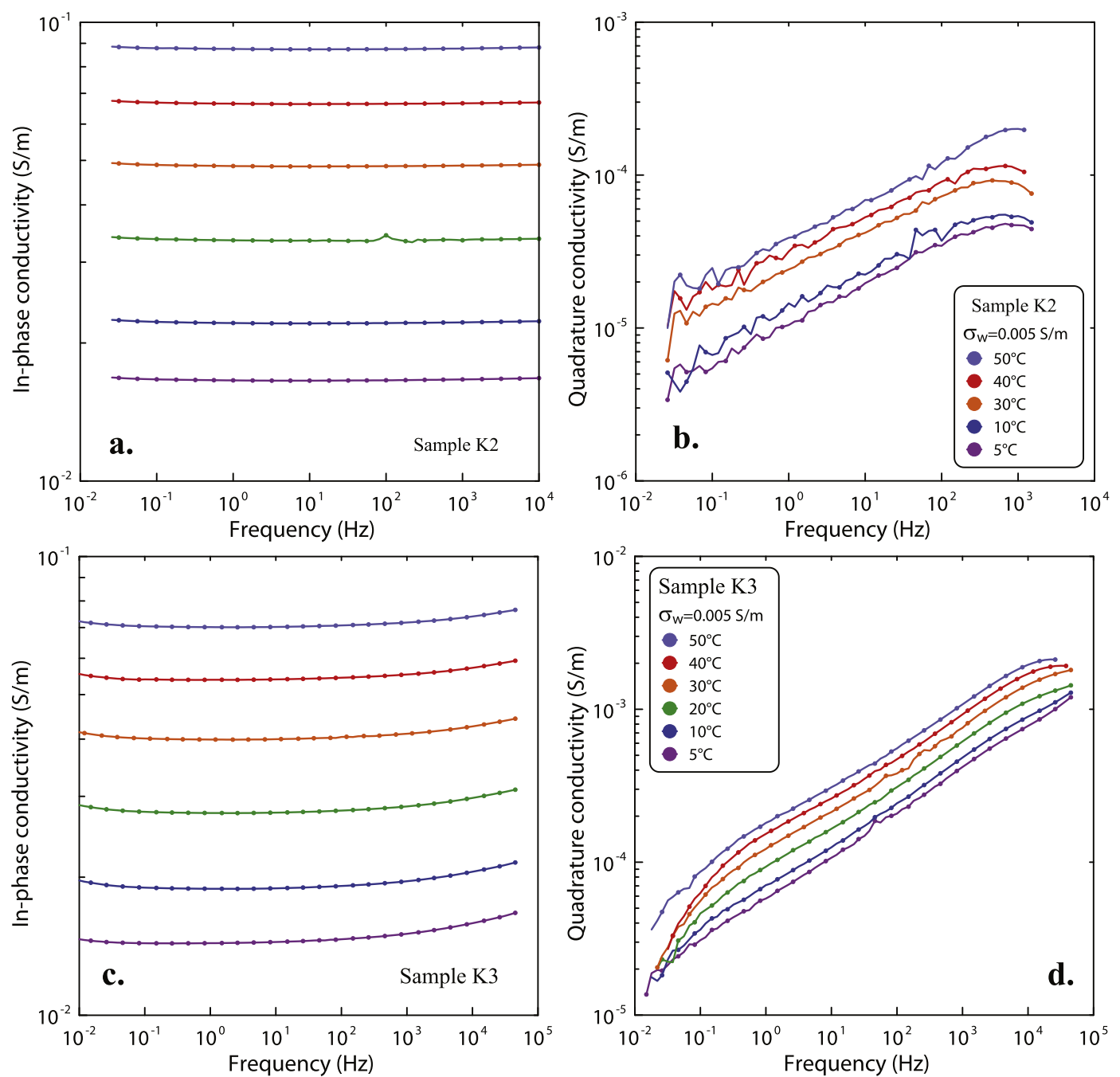

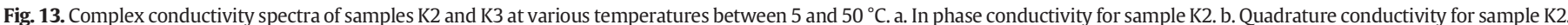

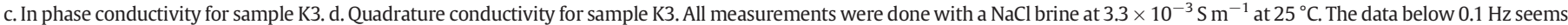
to be contaminated by noise and are not considered further.

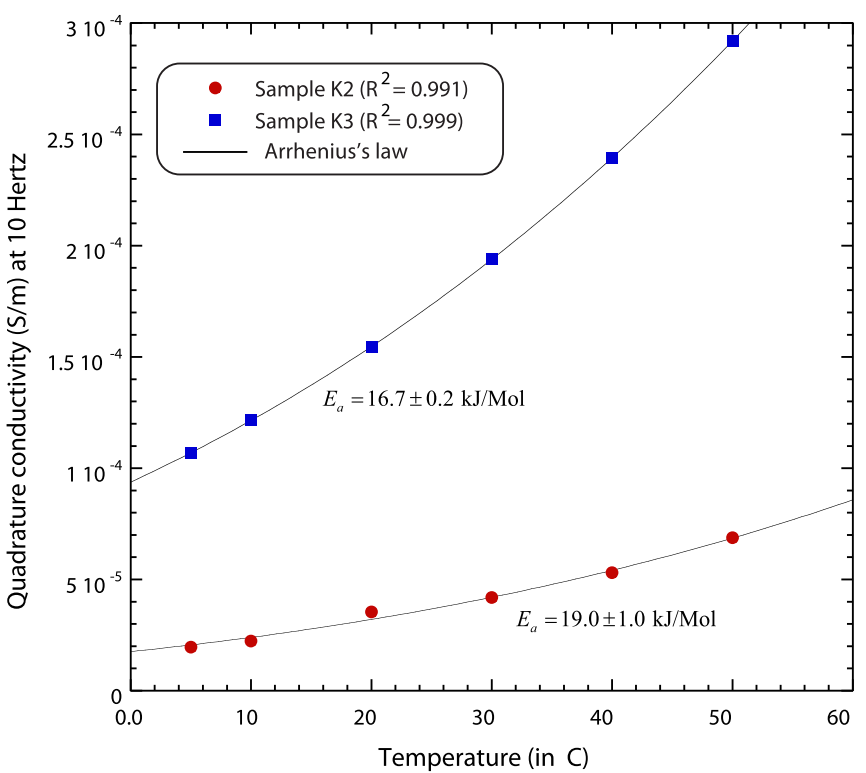

Fig. 14. Temperature dependence of the quadrature conductivity at $10 \mathrm{~Hz}$ for the two core samples $\mathrm{K} 2$ and $\mathrm{K} 3$. All measurements were done with a $\mathrm{NaCl}$ brine at $3.3 \times 10^{-3} \mathrm{~S} \mathrm{~m}^{-1}$ at $25^{\circ} \mathrm{C}$. $E_{a}$ denotes the activation energy entering Arrhenius law and its value is obtained by fitting the data using a Gauss-Newton approach.

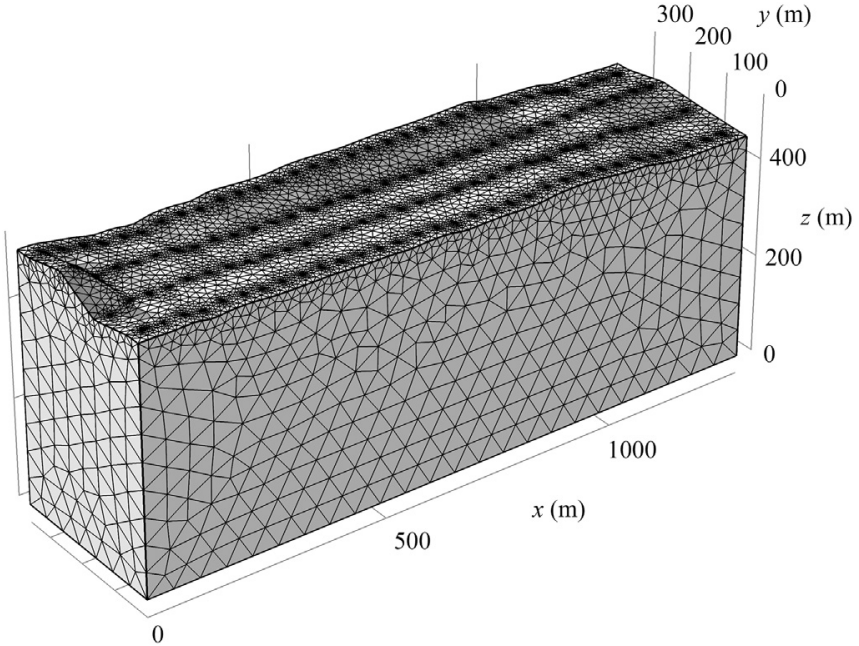

Fig. 15. Mesh of the core region used for the finite-element forward modeling and inversion of the electrical conductivity and chargeability at Site 1 (4 profiles). The mesh is refined in the vicinity of the electrodes taking into account the topography. It contains a total 86,460 elements. 


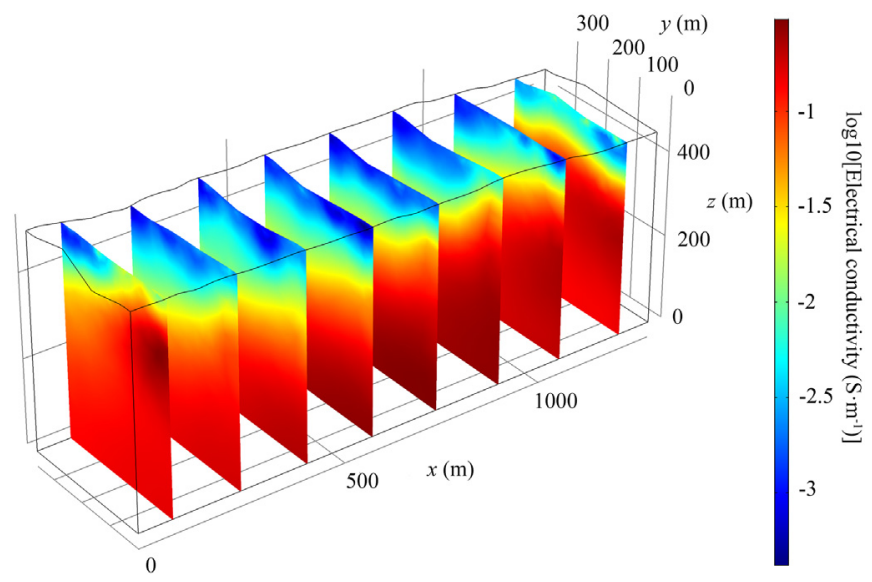

Fig. 16. 3D electrical conductivity tomogram (in $\mathrm{S} \mathrm{m}^{-1}$ ) of the Krafla Site 1 in Iceland. The inverted model of electrical conductivity reveals the presence of a low electrical conductivity near surface layer, which is identified as unaltered porous basalt. In turn, this layer covers a high conductivity cap corresponding to the smectite-zeolite cap of the geothermal system.

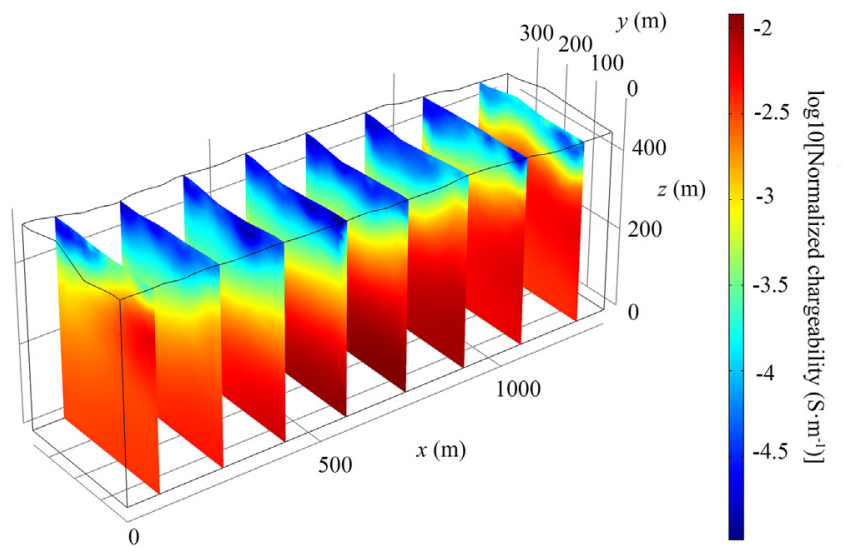

Fig. 17. 3D normalized chargeability tomogram of the Krafla Site 1 in Iceland. The inverted model of normalized chargeability confirms the presence of an unaltered porous basalt layer characterized by low normalized chargeability values. This shallow layer covers in turn smectite-zeolite cap characterized by high normalized chargeability values.

transition to the low conductivity layer reflects the transition from smectite to chlorite to mixed clays, chlorites, and epidote as temperature exceeds $240{ }^{\circ} \mathrm{C}$ (Árnason et al., 2000, 2010). At greater depth a

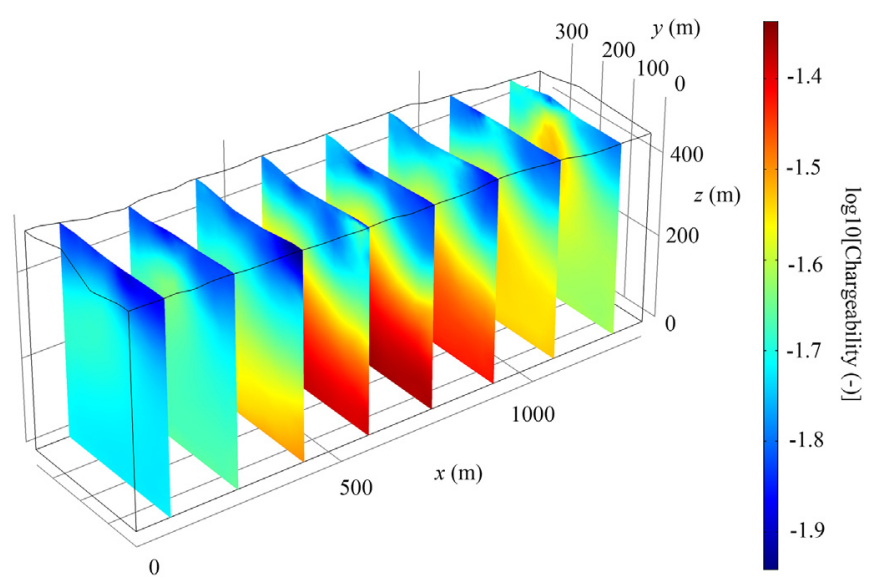

Fig. 18. 3D chargeability tomogram of the Krafla Site 1 in Iceland. Note that the chargeability cannot be higher than $8 \times 10^{-2}$ (i.e., $\log R=-1.10$ ) except in presence of a high proportion of magnetite.

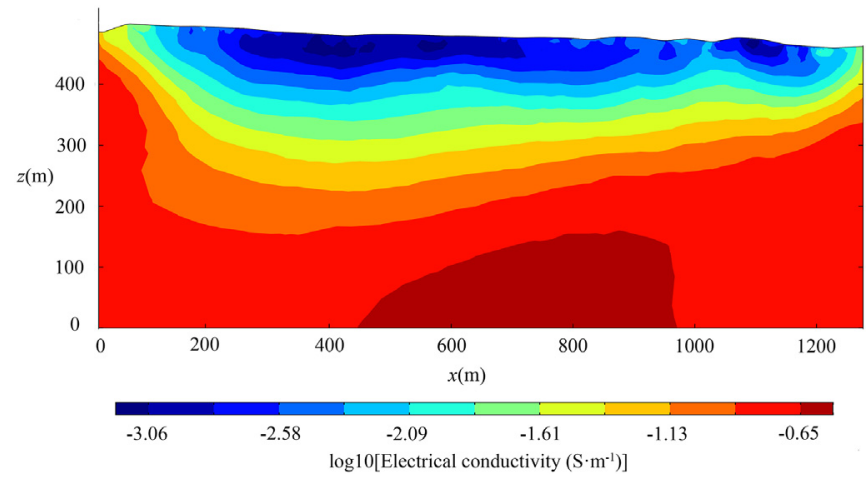

Fig. 19. 2D cross-section of electrical conductivity extracted from the 3D tomogram along Profile 2 (Site 1). The low electrical conductivity near surface layer is identified as unaltered porous basalts covering a high conductivity smectite/zeolite rich cap.

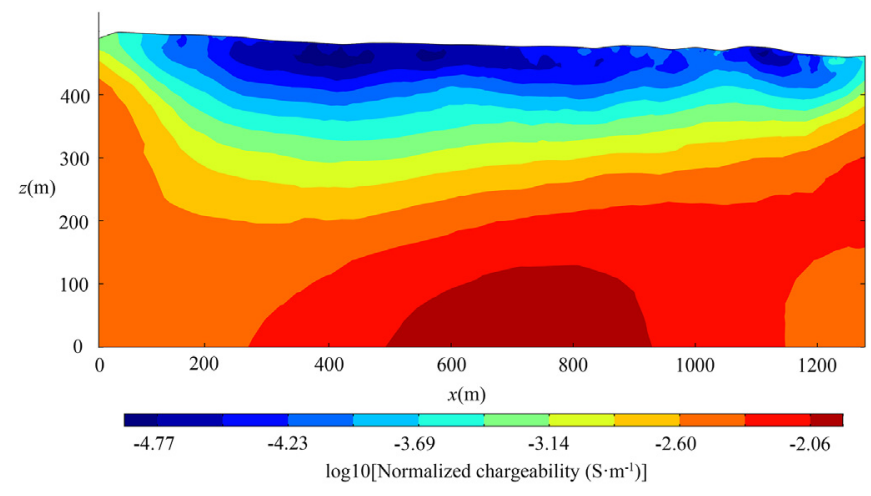

Fig. 20. 2D contour cross-section of normalized chargeability extracted from the 3D tomogram (Profile 2, Site 1). The low normalized chargeability near surface layer is identified as unaltered porous basalts covering a high normalized chargeability smectite/zeolite rich cap.

second deep conductor is seen in the inner caldera with upper boundary at the depth of $2.5-12 \mathrm{~km}$ and thickness of some tens of kilometers (Árnason et al., 2010). These deep conductors become more prominent with increasing depth within the inner caldera to the depth of about $6 \mathrm{~km}$ below sea level. Below $8 \mathrm{~km}$ bsl (below sea level), high conductivity starts to spread out of the inner caldera and below $10 \mathrm{~km}$ bsl low resistivity is seen in the whole study area. These deep conductors are possibly associated with brines and magmatic melts. Note that electrical conductivity cannot distinguish between both, we expect that in the future, induced polarization could achieve such a goal.

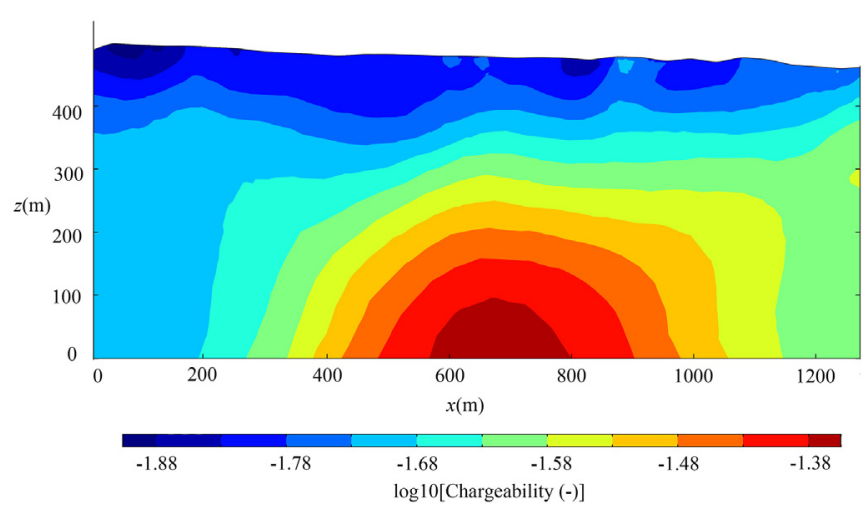

Fig. 21. 2D contour cross-section of chargeability extracted from the 3D tomogram (Profile 2, Krafla Site 1 in Iceland). The chargeability is very low in the whole section. 


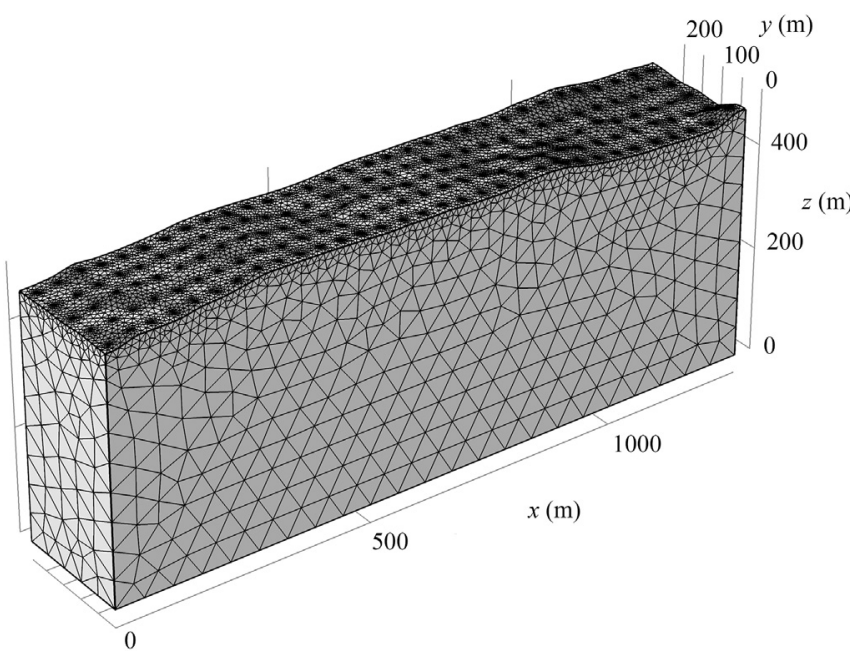

Fig. 22. Mesh of the core region used for the finite-element forward modeling and inversion of the electrical conductivity and chargeability at Krafla Site 2 (5 profiles, see Fig. 4). The mesh is refined close to the position of the electrodes and contains a total 85,074 elements.

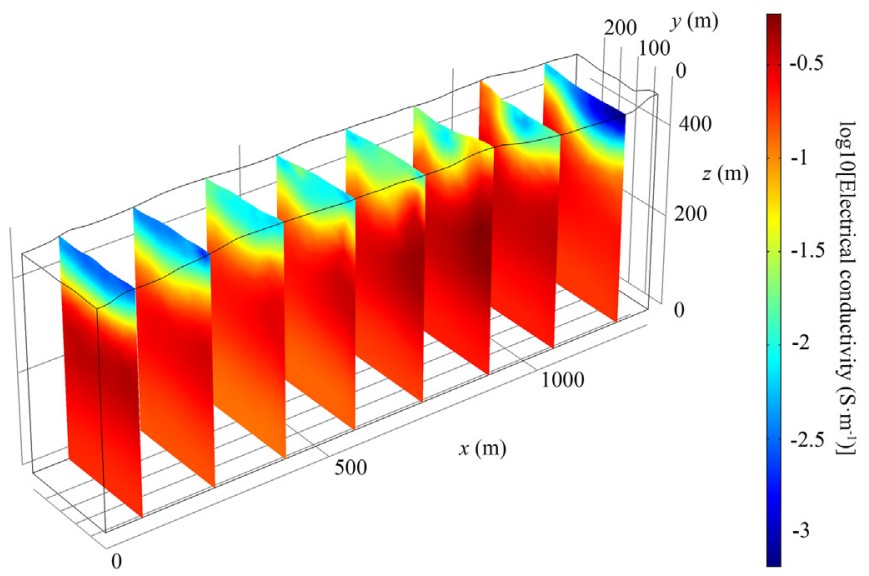

Fig. 23. 3D electrical conductivity tomogram of Site 2 (see position in Fig. 4). The magnitude of the electrical conductivity increases with depth like at Site 1 showing the interface between the unaltered basalts and the clay cap.

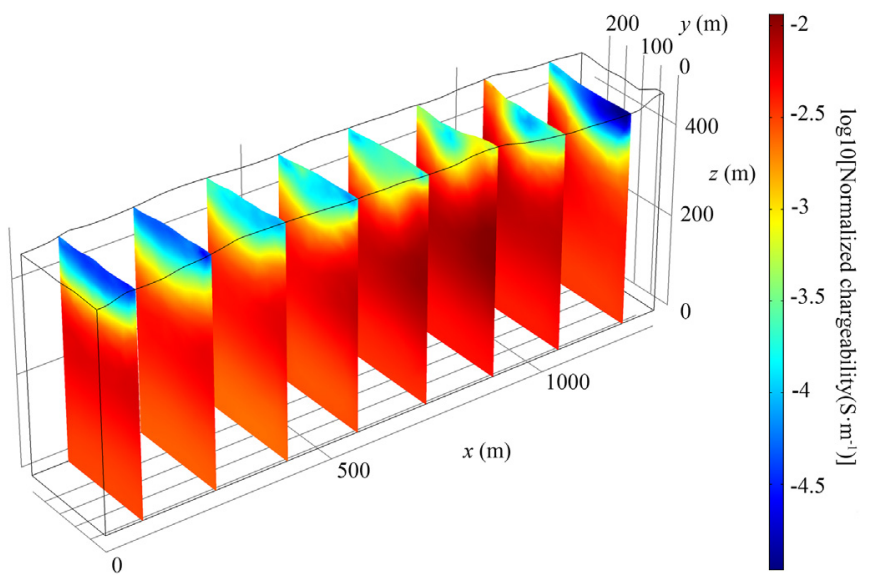

Fig. 24. 3D normalized chargeability tomogram of the Krafla Site 2 in Iceland. Overlays have low normalized chargeability (unaltered basalts) while below approximately $100 \mathrm{~m}$, we are in the smectite/zeolite clay cap characterized by large normalized chargeability values like in Profile 1.

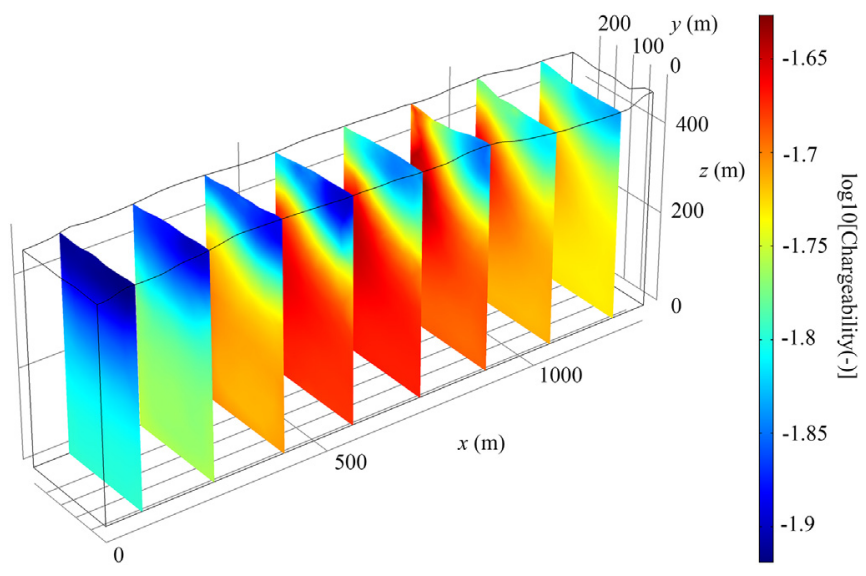

Fig. 25. 3D chargeability tomogram of the Krafla Site 2 in Iceland. The chargeability cannot be higher than $8 \times 10^{-2}$.

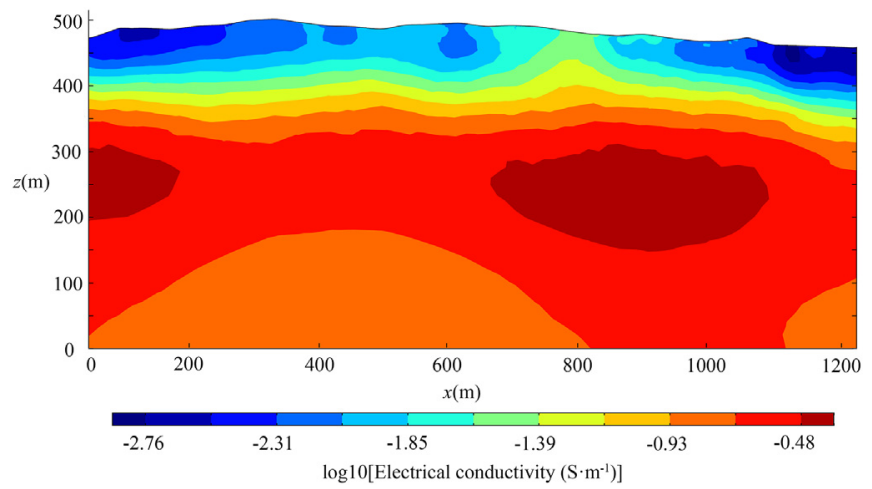

Fig. 26. 2D contour cross-section of electrical conductivity extracted from the 3D tomogram with the position of Profile 3 in the Krafla Site 2 in Iceland. Like at Site 1, the inverted model of electrical conductivity reveals the presence of a low electrical conductivity near surface layer, which is identified as unaltered porous basalt. In turn, this shallow layer overlays a high conductivity cap corresponding to the smectite-zeolite cap of the geothermal system.

\subsection{Interpretation of the long profile}

Árnason et al. (2010) mentioned that there are very few evidences of the inner caldera on the ground surface with the exception of some volcanic fissures in the eastern slopes of Krafla. This caldera is buried by younger volcanic products. The same applies to the SE sector of the outer caldera. So one of our goals was to see if these caldera rims

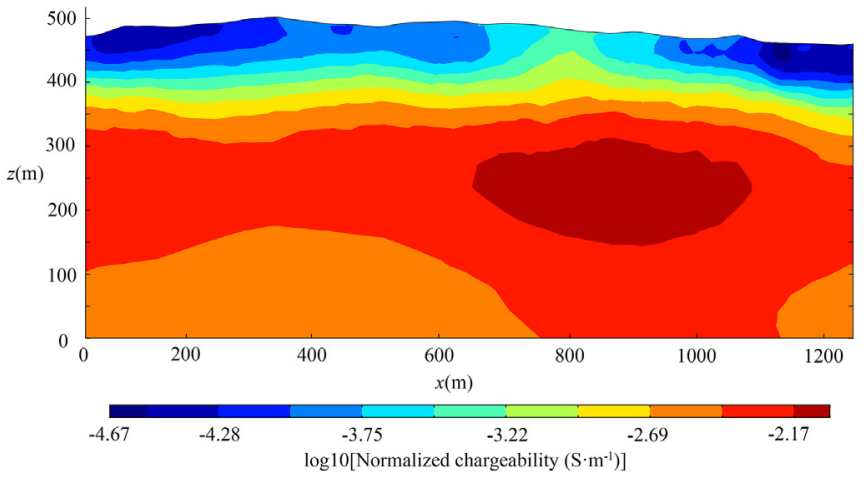

Fig. 27. 2D contour cross-section of normalized chargeability extracted from the 3D tomogram with the position of Profile 3 in the Krafla Site 2 in Iceland. We observe again the poorly altered basaltic rocks overlying the smectite/zeolite-rich cap. 


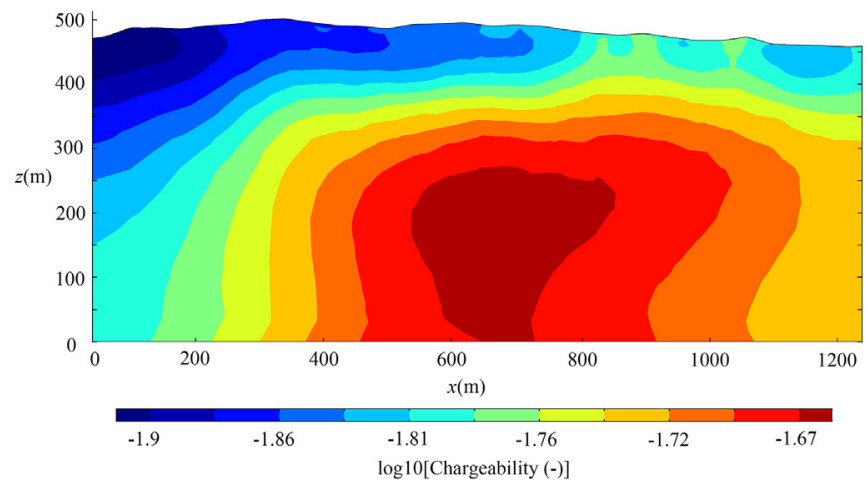

Fig. 28. 2D contour cross-section of chargeability extracted from the 3D tomogram with the position of Profile 3 in the Krafla Site 2 in Iceland.

would show up in our long profile (Fig. 29). Indeed this profile is supposed to cross twice the SE caldera rims. In the central part of the profile (ca. $2900 \mathrm{~m}$ ) we can identify clear vertical structures possibly related to the inner Krafla caldera boundary. In the SW sector of the profile, at a distance between 500 and $1000 \mathrm{~m}$ from the beginning of the profile, a series of vertical structures are probably related to both the inner (ca. $1000 \mathrm{~m}$ ) and outer (ca. $500 \mathrm{~m}$ ) Krafla caldera boundaries.

The long profile seems to show the feeder dike associated with the Obsidian Ridge (Hrafntinnuhryggur). The conductivity of the Obsidian Ridge is on the order of $10^{-4} \mathrm{~S} \mathrm{~m}^{-1}(10 \mathrm{k} \Omega \mathrm{m})$. In the Eastern part of the profile, the self-potential survey does not show any specific trend or anomalies. This is consistent with the fact that the clay cap is impermeable and geothermal activity is confined below it. In the central part of the profile (Fig. 29), we have a typical negative self-potential anomaly associated with infiltration and gravitational flow along the slopes of the topographic feature. The position of faults is not associated with large self-potential anomalies indicating some sealing effects.

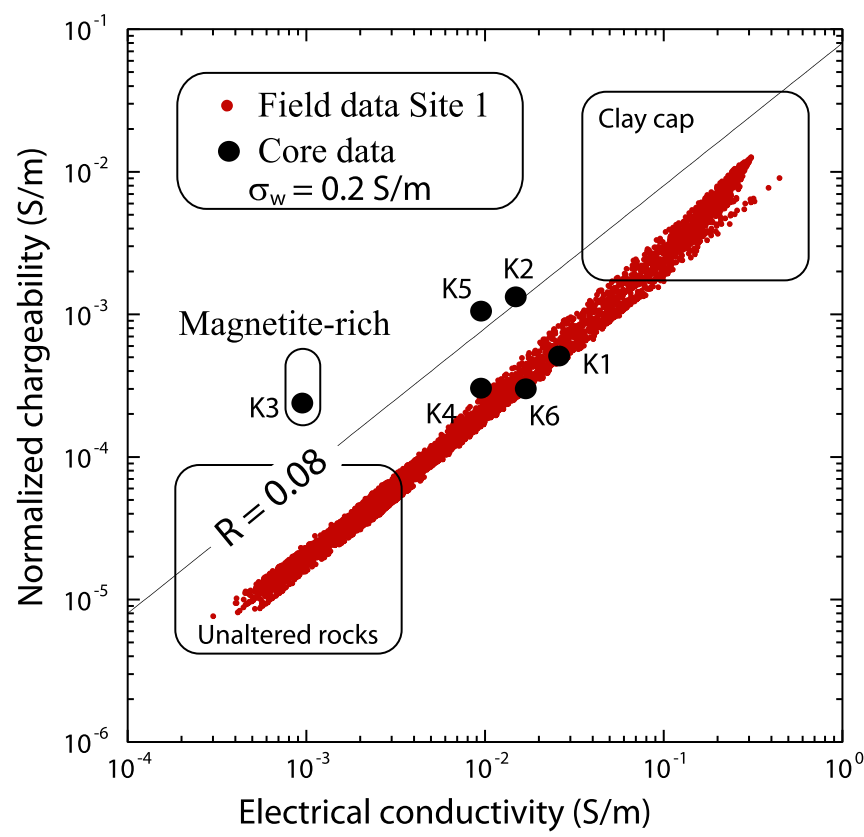

Fig. 30. Normalized chargeability versus electrical conductivity for Site 1 . The slope (0.031) is smaller than the maximum value of $R=0.08$ in absence of metallic particles. Sample K3, characterized by a high content of magnetite (see Table 1), does not seem to be representative of the in situ value.

\subsection{Tomography of porosity and cation exchange capacity}

We can now combine the petrophysical results with the geophysical data in order to image the porosity and cation exchange capacity. The methodology we used is described in details in Appendix A. We first display the normalized chargeability as a function of the electrical conductivity (Fig. 30). If surface conductivity would dominates the electrical

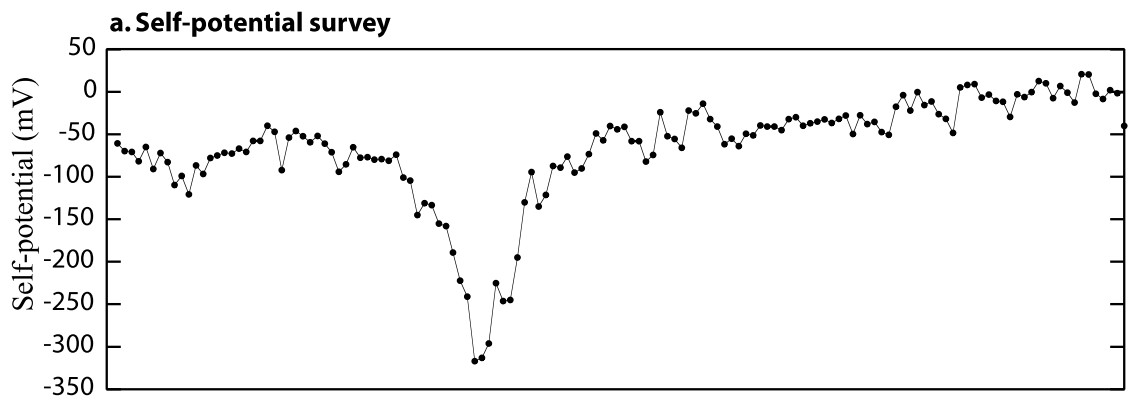

\section{b. Electrical conductivity survey}

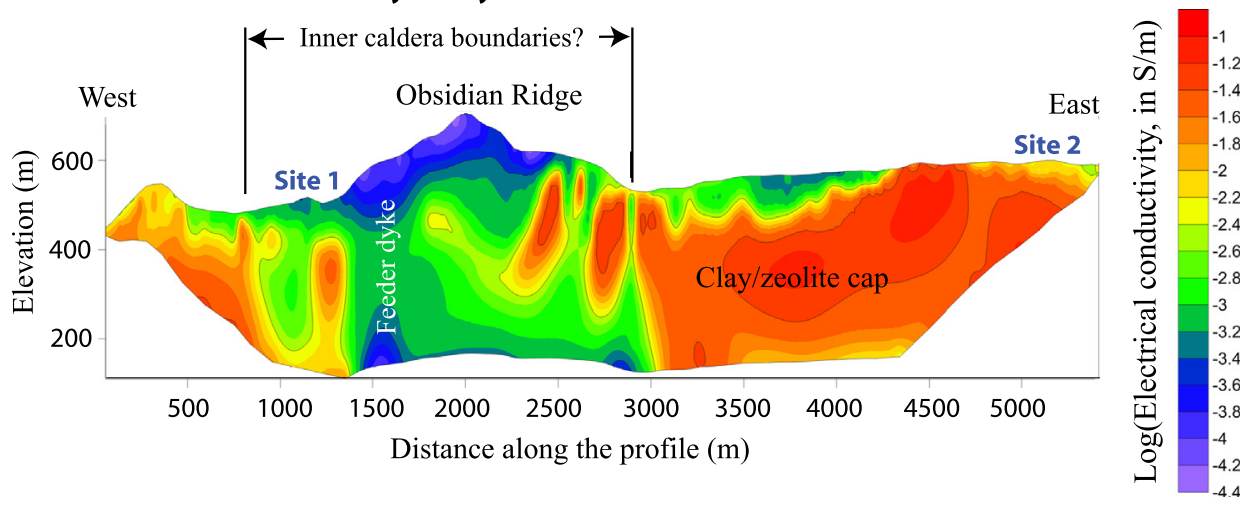

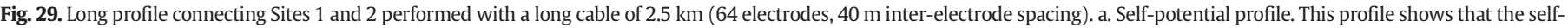

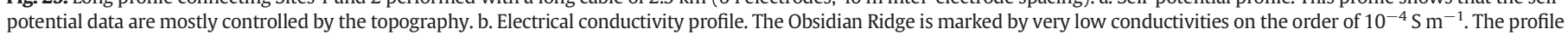
has been done using a roll-along of the electrodes ( 16 at a time). We did not performed apparent chargeability measurements for this profile. 


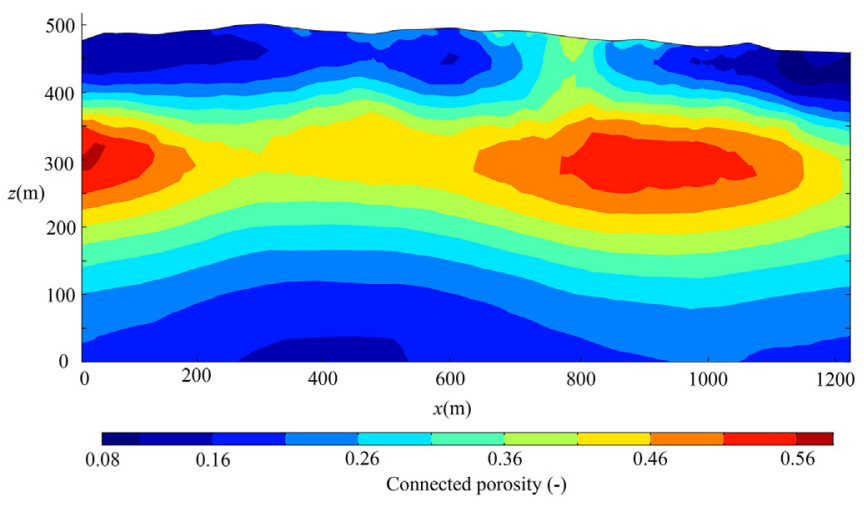

Fig. 31. Computed porosity tomogram using electrical conductivity tomography and chargeability tomography (see Appendix A) at Site 2. In the upper section of the tomogram, which is likely unsaturated, the computed porosity can be assimilated to the water content rather than a true porosity. The high porosity layer may correspond to the clay cap. We have assumed a pore water conductivity of $0.25 \mathrm{~S} \mathrm{~m}^{-1}$ at $25^{\circ} \mathrm{C}$.

conductivity of the volcanic rocks, the trend would be close to $M=R=$ 0.08 in absence of metallic particles (see Eq. (11)). When this limit is reached, the conductivity and the normalized chargeability are proportional to each other and it is not possible to determine independently the porosity and the CEC. Instead the slope is close to $M=0.031$. This means that surface conductivity plays an important role but does not entirely dominates the conductivity response of these volcanic rocks. This is also consistent with the data reported in Fig. 7. This is what we have been able to determine the water content and the CEC.

We consider now the profile shown in Fig. 26 and using the equations described in Appendix A, we determine the porosity and CEC tomograms. These tomograms are displayed in Figs. 31 and 32, respectively. We observe that the porosity is in the range 0.08 to 0.60 . The upper layer may be however unsaturated and in this vadose zone, this is more the water content that is plotted rather than the porosity. The CEC is in the range 0.4 to $4.2 \mathrm{meq} / 100 \mathrm{~g}$, which is compatible with the values obtained in Table 1 . High CEC values characterize the clay cap, which is rich in smectite and zeolites.

\section{Conclusions}

We have performed petrophysical and shallow geophysical investigations in the South East part of Krafla volcano in Iceland. The following conclusions have been reached.

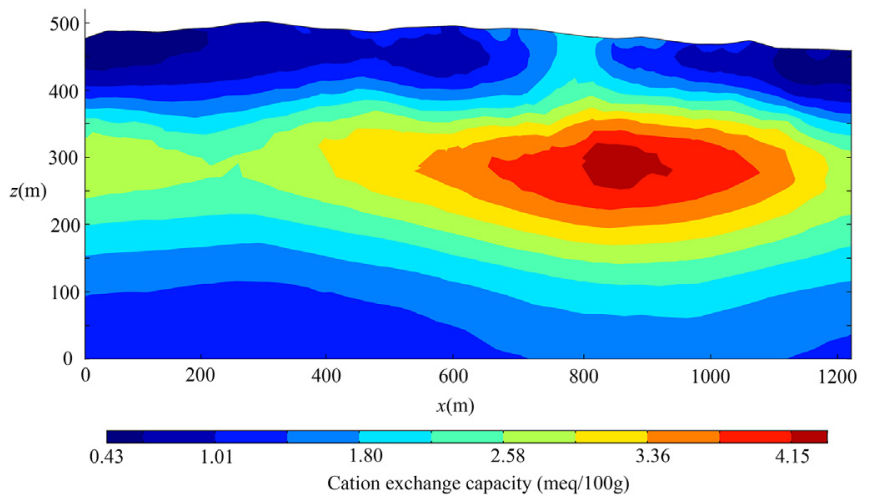

Fig. 32. Computed cation exchange capacity tomogram (CEC in meq/100 g with 1 meq $\mathrm{g}^{-1}=1 \mathrm{~mol} \mathrm{~kg}^{-1}=96,320\left(\mathrm{~kg}^{-1}\right)$ using electrical conductivity tomography and chargeability tomography (see Appendix A) at Site 2. The layer characterized by the high CEC corresponds to the clay cap. We have assumed a pore water conductivity of $0.25 \mathrm{~S} \mathrm{~m}^{-1}$ at $25{ }^{\circ} \mathrm{C}$.
(1) Petrophysical and induced polarization measurements have been performed on 6 samples from Krafla and compared with a large dataset of basaltic core samples from Hawaii. The formation factor can be related to the connected porosity with a high value of the porosity (cementation) exponent $(m=2.57 \pm 0.10)$. The surface conductivity is linearly related to the normalized CEC (cation exchange capacity divided by the tortuosity, itself the product between the formation factor by the connected porosity).

(2) In the laboratory, the quadrature conductivity and normalized chargeability scale also with the normalized CEC except for fresh samples characterized by a high content in magnetite. We expect that the samples with the highest percentage of magnetite are also the samples with the lowest CEC (less altered samples). Therefore the normalized chargeability remains a good indicator of alteration but with a low-alteration limit controlled by the presence of magnetite.

(3) In situ conductivity and induced polarization measurements show a substantial chargeability of the volcanic rocks at Krafla. Electrical conductivity and normalized chargeability in the upper $300 \mathrm{~m}$ correlates with alteration mineralogy (unaltered versus altered basalts). Surface conductivity dominates the electrical conductivity response but the bulk conductivity cannot be completely ignored. It follows that electrical conductivity at Krafla is controlled not only by temperature and the presence of fluids (water and $\mathrm{CO}_{2}$ ) but also by hydrothermal alteration products (clays and zeolites).

(4) We derive also an approach combining the electrical conductivity tomography and induced polarization tomography to image porosity and cation exchange capacity (CEC). Since CEC can be used as a proxy of alteration, the present approach can be seen as the first operational method to image alteration in geothermal fields.

(5) The long conductivity profile has been used to visualize the feeder dike of the Obsidian Ridge (Hrafntinnuhryggur) as well as the inner caldera boundaries. The electrical conductivity of the Obsidian Ridge is on the order of $10^{-4} \mathrm{~S} \mathrm{~m}^{-1}$.

\section{Acknowledgements}

The power company Landsvirkjun is thanked for providing with onsite accommodation and facilities during the field campaign. L. Lévy, F. Sigmundsson, and J. Vandemeulebrouck are thanked for co-organizing the field measurements in Krafla, as well as working in the field. S. Byrdina is thanked for developing some of the protocols. B. Gibert and University of Montpellier are thanked for partially covering the costs of material transportation to Iceland. University of Iceland and Ecole Normale Supérieure are thanked for providing with logistical support and help in the field. In that respect we especially thank S. Steinpórsson, D. Juncu, V. Drouin, M. Roger, D. Deldicque, and A. K. Árnadóttir. ISOR, and in particular S. Auðun Stefánsson, is thanked for the logistical support. K. Arnason is thanked for help in the field and fruitful discussions. This work was partly supported by a PhD grant from Ecole Normale Supérieure - Paris Sciences et Lettres to Léa Lévy and by the FrenchIcelandic program "Jules Verne", through the GAIA MUSICI project, granted to Ecole Normale Supérieure and University of Iceland. P. Briole and Ecole Normale Supérieure (UMR8538) are also thanked for providing with financial support for the field campaign. T. Ricci thanks Dr. P. Papale (INGV) for having funded his 2015 field trip. We thank CNRSINSU for funding this work. ISTerre is part of Labex OSUG@2020.We thank the referees and the Editor for the great work they have done.

\section{Appendix A. Tomogram of porosity and cation exchange capacity}

In order to derive the porosity and the CEC tomograms, we are making the following assumptions: (1) the effect of magnetite is negligible, 
(2) the porous material is fully water saturated, and (3) the porosity (cementation) exponent $m$ is close to 2 . With these assumptions and using Eqs. (7) and (8), the connected porosity and cation exchange capacity can be determined from the conductivity and normalized chargeability by,

$\phi=\sqrt{\frac{\sigma_{\infty}^{b}-M_{n}^{b} / R}{\sigma_{w}}}$

$\mathrm{CEC}=\frac{M_{n}^{b}}{\phi \rho_{g} \lambda}$

The CEC is given in $\mathrm{C} \mathrm{kg}^{-1}$ (SI units) but usually a number of studies report the CEC in meq g ${ }^{-1}\left(1 \mathrm{meq} \mathrm{g}^{-1}=1 \mathrm{~mol} \mathrm{~kg}^{-1}=96,320 \mathrm{C} \mathrm{kg}^{-1}\right)$. In Eqs. (A1) and (A2), the conductivity of the pore water and the mobility $\lambda$, which can be modeled by an Arrhenius equation,

$\sigma_{w}(T)=\sigma_{w}\left(T_{0}\right) \exp \left[-\frac{E_{a}}{k_{b} N}\left(\frac{1}{T}-\frac{1}{T_{0}}\right)\right]$,

$\lambda(T)=\lambda\left(T_{0}\right) \exp \left[-\frac{E_{a}}{k_{b} N}\left(\frac{1}{T}-\frac{1}{T_{0}}\right)\right]$,

where $T$ and $T_{0}$ are expressed in degree Kelvin (K) $\left(T_{0}=298 \mathrm{~K}\right.$, i.e., 25 $\left.{ }^{\circ} \mathrm{C}\right), k_{b} N=8.314 \mathrm{~J} \mathrm{~mol}^{-1} \mathrm{~K}^{-1}, E_{a}=16 \mathrm{~kJ} \mathrm{~mol}^{-1}$, and $\lambda\left(\mathrm{Na}^{+}, 25^{\circ} \mathrm{C}\right)$ $=3.46 \times 10^{-10} \mathrm{~m}^{-2} \mathrm{~s}^{-1} \mathrm{~V}^{-1}$. The quantities $\sigma_{\infty}{ }^{b}$ and $M_{n}^{b}$ are measured at the in situ temperature, so they don't need to be corrected for the effect of the temperature. We need to know the geothermal gradient in order to compute the temperature as a function of depth. In the upper part of the investigated system, the temperature varies linearly with depth down to a depth of $400 \mathrm{~m}$,

$T(z)=T_{S}+G z$

with $T_{S}=0{ }^{\circ} \mathrm{C}$ (surface temperature) and a geothermal gradient of $G=$ $500^{\circ} \mathrm{C} / \mathrm{km}$ (Árnason et al., 2010). From Eq. (A5), we can therefore determine the temperature with depth. Then, using Eqs. (A3) and (A4), we can compute the conductivity of the pore water and the mobility $\lambda$ as a function of depth. We need however the conductivity of the pore water at a reference temperature of $25^{\circ} \mathrm{C}$. The study by Stefánsson (2014) suggests that the Total Dissolved Solid of the pore water at Krafla well IDDP\#1 is around 300 ppm. Using the relationship of Iyasele and Idiata (2015),

$\operatorname{TDS}(\mathrm{ppm})=0.64 \sigma_{w}\left(25^{\circ} \mathrm{C}, \mu \mathrm{S} / \mathrm{cm}\right)$,

this yields a pore water conductivity $\sigma_{w}\left(T_{0}=25^{\circ} \mathrm{C}\right)=470 \mu \mathrm{S} \mathrm{cm} \mathrm{cm}^{-1}$ $\left(0.05 \mathrm{~S} \mathrm{~m}^{-1}\right)$. According to Árnason et al. (2010), fluids in the Krafla system are generally quite dilute with a TDS in the range 1000-2000 ppm, which yields a pore water conductivity in the range 1500 to 3000 $\mu \mathrm{S} \mathrm{cm}^{-1}\left(0.15\right.$ to $\left.0.30 \mathrm{~S} \mathrm{~m}^{-1}\right)$ at $T_{0}=25^{\circ} \mathrm{C}$. Another estimate is provided by Flóvenz et al. (2005) with a pore water conductivity for Krafla of 780 $\mu \mathrm{Sm}^{-1}\left(0.08 \mathrm{~S} \mathrm{~m}^{-1}\right)$ at $T_{0}=25^{\circ} \mathrm{C}$.

\section{References}

Aran, D., Maul, A., Masfaraud, J., 2008. A spectrophotometric measurement of soil cation exchange capacity based on cobaltihexamine chloride absorbance. Compt. Rendus Geosci. 340 (12), 865-871. https://doi.org/10.1016/j.crte.2008.07.015.

Árnason, K., Karlsdóttir, R., 1996. Vidnámsmaelingar í Kröflu. Orkustofnun, report OS96005/JHD-03 (96 pp.).

Árnason, K., Magnússon, I.T., 2001. Nidurstödur vidnámsmaelinga í Kröflu, OS-2001/062 (143 pp.).

Árnason, K., Karlsdóttir, R., Eysteinsson, H., Flóvenz, Ó.G., Guðlaugsson, S.Th., 2000. The resistivity structure of high-temperature geothermal systems in Iceland. Proceedings of the WGC 2000, Japan, pp. 923-928.

Árnason, K., Már Vilhjálmsson, A., Björnsdóttir, T., 2010. A Study of the Krafla Vocano Using Gravity Micro-earthquake and MT Data. Presented at Short Course V on
Exploration for Geothermal Resources, Organized by UNU-GTP, GDC and KenGen, at Lake Bogoria and Lake Naivasha, Kenya, Oct. 29-Nov. 19, 2010.

Barde-Cabusson, S., Bolós, X., Pedrazzi, D., Lovera, R., Serra, G., Martí, J., Casas, A., 2013. Electrical resistivity tomography revealing the internal structure of monogenetic volcanoes. Geophys. Res. Lett. 40, 2544-2549. https://doi.org/10.1002/grl.50538.

Bernard, M.-L., Zamora, M., Géraud, Y., Boudon, G., 2007. Transport properties of pyroclastic rocks from Montagne Pelée volcano (Martinique, Lesser Antilles). J. Geophys. Res. 112, B05205. https://doi.org/10.1029/2006JB004385.

Bigalke, J., Grabner, E.W., 1997. The geobattery model: a contribution to large-scale electrochemistry. Electrochim. Acta 42, 3443-3452. https://doi.org/10.1016/S0013-4686 (97)00053-4.

Birch, F.S., 1993. Testing Fournier's method for finding water table from self-potential. Ground Water 31, 50-56.

Birch, F.S., 1998. Imaging the water table by filtering self-potential profiles. Ground Water 36, 779-782.

Bjornsson, G., Gunnlaugsson, E., Hjartarson, A., 2006. Applying the Hengill geothermal model in power plant decision making and environmental impact studies. Proceedings: TOUGH Symposium 2006, Lawrence Berkeley National Laboratory, Berkeley, California, May 15-17, 2006.

Broyden, C.G., 1965. A class of methods for solving nonlinear simultaneous equations. Math. Comput. 19 (92), 577-593. https://doi.org/10.1090/S0025-5718-19650198670-6 (American Mathematical Society, JSTOR 2003941).

Brunauer, S., Emmett, P.H., Teller, E., 1938. Adsorption of gasses in multimolecular layers. J. Am. Chem. Soc. 60 (2), 309-319. https://doi.org/10.1021/ja01269a023.

Buck, W.R., Einarsson, P., Brandsdóttir, B., 2006. Tectonic stress and magma chamber size as controls on dike propagation: constraints from the 1975-1984 Krafla rifting episode. J. Geophys. Res. 111, B12404. https://doi.org/10.1029/2005JB003879.

Ciesielski, H., Sterckemann, T., 1997. Determination of exchange capacity and exchangeable cations in soils by means of cobalt hexamine trichloride. Effects of experimental conditions. Agronomie 17, 1-7. https://doi.org/10.1051/agro:19970101.

Corwin, R.F., 1989. Data quality for engineering self-potential surveys. Proceedings, International Symposium on the Detection of Subsurface Flow Phenomena, Lecture Notes in Earth Sciences. Springler-Verlag, Berlin, pp. 51-72.

Dahlin, T., Leroux, V., Nissen, J., 2002. Measuring techniques in induced polarisation imaging. J. Appl. Geophys. 50, 279-298.

Drouin, V., Heki, K. Sigmundsson, F., Hreinsdóttir, F. Ófeigsson, B.G. 2016. Constraints on seasonal load variations and regional rigidity from continuous GPS measurements in Iceland, 1997-2014. Geophys. J. Int. 205 (3), 1843-1858.

Drouin, V., Sigmundsson, F., Ófeigsson, B.G., Hreinsdóttir, S., Sturkell, E., Einarsson, P., 2017. Deformation in the northern volcanic zone of Iceland 2008-2014: an interplay of tectonic, magmatic and glacial isostatic deformation. J. Geophys. Res. 122 (4), 3158-3178. https://doi.org/10.1002/2016JB013206.

Einarsson, P., 1991. Umbrotin vid Kröflu 1975-89. In: Gardarsson, A., Einarsson, A. (Eds.), Náttúra Mývatns. 2. Hid íslenska náttúrufrædifélag, Reykjavík, pp. 96-139.

Finizola, A., Ricci, T., Deiana, R., Cabusson, S.B., Rossi, M., Praticelli, N., Giocoli, A., Romano, G., Delcher, E., Suski, B., 2010. Adventive hydrothermal circulation on Stromboli volcano (Aeolian Islands, Italy) revealed by geophysical and geochemical approaches: implications for general fluid flow models on volcanoes. J. Volcanol. Geotherm. Res. 196 (1), 111-119

Florsch, N., Llubes, M., Téreygeol, F., Ghorbani, A., Roblet, P., 2010. Quantification of slag heap volumes and masses through the use of induced polarization: application to the Castel-Minier site. J. Archaeol. Sci. 38 (2), 438-451. https://doi.org/10.1016/j. jas.2010.09.027.

Flóvenz, O.G., Spangenberg, E., Kulenkampff, J., Árnason, K., Karlsdóttir, R., Huenges, E., 2005. The Role of Electrical Interface Conduction in Geothermal Exploration, Proceedings World Geothermal Congress 2005, Antalya, Turkey, 24-29 April 2005.

Fridleifsson, G.O., Armannsso, H., Mortenen, A.K. 2006. Geothermal conditons in the Krafla caldera with focus on wel KG-26. Review in Ration to the Iceland Drilling Project. Report ISOR-2006/030 (38 pp.).

Ghorbani, A., Camerlynck, C., Florsch, N., Cosenza, P., Tabbagh, A., Revil, A., 2007. Bayesian inference of the Cole-Cole parameters from time and frequency-domain induced polarization. Geophys. Prospect. 55 (4), 589-605. https://doi.org/10.1111/j.13652478.2007.00627.x

Ghorbani, A., Revil, A., Coperey, A., Soueid Ahmed, A., Roque, S., Heap, M.J., Grandis, H., Viveiros, F., 2018. Complex conductivity of volcanic rocks and the geophysical mapping of alteration in volcanoes. J. Volcanol. Geotherm. Res. 357, 106-127.

Hansen, P.C., 1998. Rank-deficient and Discrete Ill-posed Problems: Numerical Aspects of Linear Inversion. Society for Industrial and Applied Mathematics (SIAM), Philadelphia https://doi.org/10.1137/1.9780898719697.

Herman, R., 2001. An introduction to electrical resistivity in geophysics. Am. J. Phys. 69 (9), 943-962. https://doi.org/10.1119/1.137801.

Hjartardóttir, A.R., Einarsson, P., Bramham, E., Wright, T.J., 2012. The Krafla fissure swarm, Iceland, and its formation by rifting events. Bull. Volcanol. 74, 2139-2153.

Hjartardóttir, A.R., Einarsson, P., Magnúsdóttir, S., Björnsdóttir, T., Brandsdóttir, B., 2015. Fracture systems of the northern volcanic rift zone, Iceland: an onshore part of the mid-Atlantic plate boundary. Geol. Soc. Lond. Spec. Publ. 420 (Sigvaldason 1983).

Iyasele, J.U., Idiata, D. J. 2015. Investigation of the relationship between electrical conductivity and total dissolved solids for mono-valent, di-valent and tri-valent metal compounds. Int. J. Eng. Res. Rev. 3 (1), 40-48.

Jónasson, K., 1994. Rhyolite volcanism in the Krafla central volcano, northeast Iceland. Bull. Volcanol. 56, 516-528.

Kristinsdóttir, L.H., Flóvenz, O.G., Árnason, K., Bruhn, D., Milsch, H., Spangenberg, E., Kulenkampff, J., 2010. Electrical conductivity and P-wave velocity in rock samples from high-temperature Icelandic geothermal fields. Geothermics 39, 94-105. https://doi.org/10.1016/j.geothermics.2009.12.001. 
Leroy, P., Revil, A., 2009. A mechanistic model for the spectral induced polarization of clay materials. J. Geophys. Res. 114, B10202. https://doi.org/10.1029/2008JB006114.

Leroy, P., Li, S., Jougnot, D., Revil, A., Wu, Y., 2017. Modeling the evolution of complex conductivity during calcite precipitation on glass beads. Geophys. J. Int. 209 (1), 123-140. https://doi.org/10.1093/gji/ggx001.

Lyklema, J., Dukhin, S.S., Shilov, V.N., 1983. The relaxation of the double-layer around colloidal particles and the low-frequency dielectric-dispersion. Part I. Theoretical considerations. J. Electroanal. Chem. 143 (1-2), 1-21.

Michot, D., Zahra, T., Issifou, A., 2016. Nonstationarity of the electrical resistivity and soil moisture relationship in a heterogeneous soil system: a case study. Soil 2, 241-255. https://doi.org/10.5194/soil-2-241-2016.

Olhoeft, G.R., 1985. Low-frequency electrical properties. Geophysics 50, 2492-2503.

Perrier, F., Trique, M., Lorne, B., Avouac, J.P., Hautot, S., Tarits, P., 1998. Electrical variations associated with yearly lake level variations. Geophys. Res. Lett. 25, 1955-1958.

Petiau, 2000. Second generation of lead-lead chloride electrodes for geophysical applications. Pure Appl. Geophys. 157, 357-382. https://doi.org/10.1007/s000240050004.

Qi, Y., Soueid Ahmed, A., Revil, A., Ghorbani, A., Abdulsamad, F., Florsch, N., Bonnenfant, J., 2018. Induced polarization response of porous media with metallic particles - Part 7. Detection and quantification of buried slag heaps. Geophysics 83 (5)), E277-E291. https://doi.org/10.1190/GEO2017-0760.1.

Reid, M.E., Sisson, T.W., Brien, D.L., 2001. Volcano collapse promoted by hydrothermal alteration and edifice shape, Mount Rainier, Washington. Geology 29, 779-782.

Revil, A., 2012. Spectral induced polarization of shaly sands: influence of the electrical double layer. Water Resour. Res. 48, W02517. https://doi.org/10.1029/2011WR011260.

Revil, A., 2013a. Effective conductivity and permittivity of unsaturated porous materials in the frequency range $1 \mathrm{mHz}-1 \mathrm{GHz}$. Water Resour. Res. 49, 306-327. https://doi.org/ 10.1029/2012WR012700.

Revil, A., 2013b. On charge accumulations in heterogeneous porous materials under the influence of an electrical field. Geophysics 78 (4), D271-D291. https://doi.org/ 10.1190/GEO2012-0503.1.

Revil, A., Cathles, L.M., Losh, S., Nunn, J.A., 1998. Electrical conductivity in shaly sands with geophysical applications. J. Geophys. Res. 103 (B10), 23,925-23,936.

Revil, A., Johnson, T.C., Finizola, A., 2010. Three-dimensional resistivity tomography of Vulcan's forge, Vulcano Island, southern Italy. Geophys. Res. Lett. 37 (15), L15308. https://doi.org/10.1029/2010GL043983.

Revil, A., Florsch, N., Mao, D., 2015a. Induced polarization response of porous media with metallic particles - part 1: a theory for disseminated semiconductors. Geophysics 80 (5), D525-D538. https://doi.org/10.1190/GEO2014-0577.1.

Revil, A., Abdel Aal, G.Z., Atekwana, E.A., Mao, D., Florsch, N., 2015b. Induced polarization response of porous media with metallic particles - part 2. Comparison with a broad database of experimental data. Geophysics 80 (5), D539-D552. https://doi.org/ 10.1190/GEO2014-0578.1.

Revil, A., Murugesu, M., Prasad, M., Le Breton, M., 2017a. Alteration of volcanic rocks: a new non-intrusive indicator based on induced polarization measurements. J. Volcanol. Geotherm. Res. 341, 351-362. https://doi.org/10.1016/j.jvolgeores.2017.06.016.

Revil, A., Coperey, A., Shao, Z., Florsch, N., Fabricius, I.L., Deng, Y., Delsman, J.R., Pauw, P.S., Karaoulis, M., de Louw, P.G.B., van Baaren, E.S., Dabekaussen, W., Menkovic, A., Gunnink, J.L., 2017b. Complex conductivity of soils. Water Resour. Res. 53. https:// doi.org/10.1002/2017WR020655.
Revil, A., Coperey, A., Deng, Y., Cerepi, A., Seleznev, N., 2018. Complex conductivity of tight sandstones. Geophysics 83 (2), 1-20. https://doi.org/10.1190/GEO2017-0096.1.

Sæmundsson, K., 1974. Evolution of the Axial Rifting Zone in Northern Iceland and the Tjörnes Fracture Zone. Geol. Soc. Am. Bull. 85 (4), 495-504. http://gsabulletin. gsapubs.org/content/85/4/495.abstract.

Saemundsson, K., 1983. Fractures in the Krafla area. On the status of the Krafla geotherma power station. Proceedings of Meeting Held in Akureyri. Iceland, 2-3 March 1983 pp. 4-8 (in Icelandic).

Sæmundsson, K., 1991. Jardfrædi kröflukerfisins. In: Gardarsson, A., Einarsson, A. (Eds.), Náttúra Mývatns, Ch. 1. Hid íslenska náttúrufrædifélag, Reykjavík, pp. 24-95.

Schlumberger, C., 1920. Study of Underground Electrical Prospecting, Paris (99 pp.).

Seigel, H.O., 1959. Mathematical formulation and type curves for induced polarization. Geophysics 24, 547-565. https://doi.org/10.1190/1.1438625.

Shuey, R.T., Johnson, M., 1973. On the phenomenology of electrical relaxation in rocks. Geophysics 38, 37-48. https://doi.org/10.1190/1.1440331.

Sigvaldason, G., 1983. Volcanic prediction in Iceland. In: Tazieff, H., Sabroux, J.C. (Eds.) Forecasting Volcanic Events (Developments in Volcanology). Elsevier, Amsterdam, pp. 193-213.

Soueid Ahmed, A., Revil, A., Byrdina, S., Coperey, A., Gailler, L., Grobbe, N., Viveiros, F., Silva, C., Jougnot, D., Ghorbani, A., Hogg, C., Kiyan, D., Rath, V., Heap, M.J., Grandis, H., Humaida, H., 2018. 3D electrical conductivity tomography of volcanoes. J. Volcanol. Geotherm. Res. 356, 243-263.

Stefánsson, A., 2014. Geochemical Assessment of the Utilization of IDDP\#1, Krafla (66 pp.).

Thoroddsen, T.E., 1907-1915. Skýrslur Um Mývatnselda 1724-1729. Safn til sögu Íslands. 4, pp. 385-411.

Tikhonov, A.N., Arsenin, V.Y., 1977. Solutions of Ill-posed Problems. John Wiley \& Sons, Washington https://doi.org/10.1137/1021044.

Tryggvason, E., 1984. Widening of the Krafla fissure swarm during the 1975-1981 volcano-tectonic episode. Bull. Volcanol. 47 (1), 47-69.

Tuffen, H., Castro, J.M., 2009. The emplacement of an obsidian dyke through thin ice: Hrafntinnuhryggur, Krafla Iceland. J. Volcanol. Geotherm. Res. 185, 352-366.

Vinegar, H.J., Waxman, M.H., 1984. Induced polarization of shaly sands. Geophysics 49 1267-1287.

Waxman, M.H., Smits, L.J.M., 1968. Electrical conductivities in oil bearing shaly sands. SPE J. 8, 107-122. https://doi.org/10.2118/1863-A.

Weller, A., Slater, L., Nordsiek, S., 2013. On the relationship between induced polarization and surface conductivity: Implications for petrophysical interpretation of electrical measurements. Geophysics 78 (5), D315-D325. https://doi.org/10.1190/GEO2013 0076.1.

Wong, J., 1979. An electrochemical model of the induced polarization phenomenon in disseminated sulfide ores. Geophysics 44, 1245-1265. https://doi.org/10.1190/ 1.1441005.

Zimmermann, E., Kemna, A., Berwix, J., Glaas, W., Munch, H., Huisman, J., 2008. A high accuracy impedance spectrometer for measuring sediments with low polarizability Meas. Sci. Technol. 19 (10), 105603. https://doi.org/10.1088/0957-0233/19/10/ 105603. 